\title{
A dopaminergic mechanism of antipsychotic drug efficacy, failure, and failure reversal: the role of the dopamine transporter
}

\author{
Davide Amato $\mathbb{C}^{1,2} \cdot$ Fabio Canneva ${ }^{3} \cdot$ Paul Cumming $\mathbb{C}^{4,5} \cdot$ Simone Maschauer ${ }^{4}$ - Dominik Groos ${ }^{6}$. \\ Jana Katharina Dahlmanns $\mathbb{B}^{2} \cdot$ Teja W. Grömer $^{1} \cdot$ Lisa Chiofalo $^{1} \cdot$ Marc Dahlmanns $^{1} \cdot$ Fang Zheng $^{6}$.

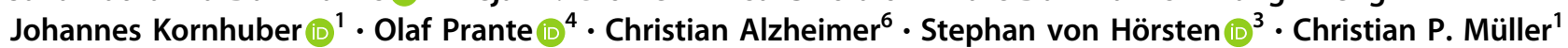

Received: 23 October 2017 / Revised: 30 April 2018 / Accepted: 25 May 2018 / Published online: 23 July 2018

(c) The Author(s) 2018. This article is published with open access

\begin{abstract}
Antipsychotic drugs are effective interventions in schizophrenia. However, the efficacy of these agents often decreases over time, which leads to treatment failure and symptom recurrence. We report that antipsychotic efficacy in rat models declines in concert with extracellular striatal dopamine levels rather than insufficient dopamine D2 receptor occupancy. Antipsychotic efficacy was associated with a suppression of dopamine transporter activity, which was reversed during failure. Antipsychotic failure coincided with reduced dopamine neuron firing, which was not observed during antipsychotic efficacy. Synaptic field responses in dopamine target areas declined during antipsychotic efficacy and showed potentiation during failure. Antipsychotics blocked synaptic vesicle release during efficacy but enhanced this release during failure. We found that the pharmacological inhibition of the dopamine transporter rescued antipsychotic drug treatment outcomes, supporting the hypothesis that the dopamine transporter is a main target of antipsychotic drugs and predicting that dopamine transporter blockers may be an adjunct treatment to reverse antipsychotic treatment failure.
\end{abstract}

Electronic supplementary material The online version of this article (https://doi.org/10.1038/s41380-018-0114-5) contains supplementary material, which is available to authorized users.

Davide Amato

amatod@musc.edu

amatodavide@gmail.com

1 Department of Psychiatry and Psychotherapy, University Clinic, Friedrich-Alexander-University Erlangen-Nürnberg, Erlangen, Germany

2 Department of Neuroscience, Medical University of South Carolina, Charleston, SC, USA

3 Department of Experimental Therapy, Preclinical Experimental Center, Friedrich-Alexander-University Erlangen-Nürnberg, Erlangen, Germany

4 Department of Nuclear Medicine, Molecular Imaging and Radiochemistry, Friedrich-Alexander-University ErlangenNürnberg, Erlangen, Germany

5 School of Psychology and Counselling and IHBI, Queensland University of Technology, and QIMR Berghofer Medical Research Institute, Brisbane, Australia

6 Institute of Physiology and Pathophysiology, Friedrich-AlexanderUniversity Erlangen-Nürnberg, Erlangen, Germany

\section{Introduction}

Antipsychotic drugs (APDs) are a mainstay in the treatment of schizophrenia. The available APDs exhibit a large spectrum of mechanisms and act on receptors of diverse biogenic monoamine neurotransmitters [1]. However, $D_{2}$ receptor blockade is a common property of effective APD medications [2]. It is often suggested that the maximal clinical response is achieved when APDs block $\sim 65-75 \%$ of $\mathrm{D}_{2}$ receptors and is negligible when $D_{2}$ receptor occupancy is below this therapeutic window [3, 4]. However, a growing body of evidence appears to cast doubt on the causal effect of this mechanism [5]. Although antipsychotic therapeutic efficacy may appear positively associated with receptor blockade at the beginning of the treatment, APDs exhibit declining therapeutic efficacy with long-term treatment even though their receptor occupancy remains fairly stable. Clinical Antipsychotic Trials of Intervention Effectiveness (CATIE) studies define the incremental lack of antipsychotic efficacy as one of the main factors of drug discontinuation, which was observed within 18 months after treatment initiation in $75 \%$ of patients [6-8]. Related to this acquired pharmacological resistance, $\sim 20 \%$ of all schizophrenia patients will never respond to APDs, even if a consistent $\mathrm{D}_{2}$ receptor occupancy is maintained at the start 
of the treatment within the therapeutic window [9-11]. Additionally, clinical evidence shows that there is indeed a relationship between early response/no-response and longterm antipsychotic outcomes [12]. While the heterogeneous neurobiology underlying schizophrenia symptoms could lead to multiple antipsychotic responses, the pharmacological mechanisms beyond $\mathrm{D}_{2}$ receptors regulating APD treatment efficacy and failure still await clarification. In this study we bridge this gap by modelling APD treatment efficacy and failure in psychopathologically naïve animals. Specifically, we aimed to recapitulate APD-driven neuroadaptations that can contribute to core clinical issues including long-term lack of efficacy, relapse and APD treatment-resistance. To understand the neurobiology of APDs efficacy and failure, we probed the underlying neurochemical and neurophysiological mechanisms and developed a rational pharmacological intervention to ameliorate the loss of APD effects.

\section{Materials and Methods}

\section{Animals}

Male Sprague-Dawley rats (Charles River Laboratories, Germany) weighing 250-300 g were used for most of the studies. Male C57B1/6 6-week old mice (Charles River Laboratories, Germany) were used for the electrophysiology studies only. All experiments were performed in accordance with the Animal Protection Law of the Federal Republic of Germany and the European Communities Council Directive of 24 November 1986 (86/609/EEC), and local authorities approved all study protocols.

\section{Drugs and treatment methods}

We used clinical equivalent doses of haloperidol (HAL) and olanzapine (OLA), as described in the supplementary material based on previous work [13, 14]. D-amphetamine (AMPH) and the dopamine transporter (DAT) blocker GBR 12909 were administered intraperitoneally (i.p.). GBR 12909 was also administered locally into the $\mathrm{CPu}$ (left and right sides) at $20 \mu \mathrm{g}$ in $1 \mu \mathrm{l}$ volume per side, according to previously described procedures $[15,16]$. A challenge of $100 \mathrm{mM}$ potassium chloride $\left(\mathrm{K}^{+}\right)$was delivered for $80 \mathrm{~min}$ to the medial prefrontal cortex (mPFC), caudate-putamen $(\mathrm{CPu})$, and nucleus accumbens (NAcc) via reverse dialysis, as previously described [17]. Full methodological procedures are described in the supplementary material.

\section{Behavior}

Locomotion, acoustic startle reflex (ASR) and pre-pulse inhibition (PPI) were recorded prior to and after either vehicle (veh) or AMPH (3 mg/kg) injections or in response to a tail-pinch (TP). We monitored the ability of HAL ( 2 and 14 days) and OLA (2, 6, 14, and 21 days) to inhibit the AMPH-induced behavioral disruptions. Additional methodological details are described in the supplementary material.

\section{Microdialysis and behavior}

Microdialysis studies were coupled with behavioral analyses according to previous protocols [13, 14]. Particularly, we investigated the efficacy of HAL (6 and 14 day) and OLA (2, 6, and 21 days) to inhibit dopamine release and locomotion induced by a TP. We also measured the effect of systemic and intrastriatal (according to previous procedures [15, 16]) GBR12909 injections in the reversal of HAL treatment failure. Further details are described in the supplementary material.

\section{Western blot analysis and PCR studies}

DAT, serotonin (SERT), and noradrenaline transporters (NET) and tyrosine hydroxylase (TH) protein expression levels were measured using standard Western blot analysis in brain samples from rats treated with chronic veh or HAL (see Methods section in supplementary material and Figure S4). We also measured DAT expression levels after OLA treatment (supplementary Figure S5). Brain tissue was acquired at 2, 6, and 14 days of treatment, and the regions of interest $(\mathrm{CPu}, \mathrm{NAcc}$, and $\mathrm{PFC})$ were rapidly dissected on ice, according to previous methods [18]. We also determined the nigrostriatal and mesolimbic DAT mRNA expression after veh or HAL treatment. The DAT mRNA expression levels were quantified in freshly dissected portions of striatum using a standard reverse transcriptasecoupled quantitative real-time PCR (qRT-PCR) procedure and the primer pairs DAT-for-AGCTACCATGCCCTA TGTGG and DAT-rev-ATCAGCACTCCAAACCCAAC (see supplementary material for details).

\section{MicroPET brain study}

We determined striatal dopamine $\mathrm{D}_{2 / 3}$ receptor and DAT availability according to previously described methods using $\left[{ }^{18} \mathrm{~F}\right]$ fallypride $[19]$ and $\left[{ }^{18} \mathrm{~F}\right] \mathrm{FP}-\mathrm{CMT}$ [20], respectively (see details in the supplementary material). To be conform with the literature we will use " $\mathrm{D}_{2}$ " instead of " $\mathrm{D}_{2 / 3}$ " receptors. We measured striatal dopamine $\mathrm{D}_{2}$ receptor availability after 14 days of treatment with veh or HAL. Image reconstruction was performed as described previously $[20,21]$, and parametric maps of the binding potential $\left(\mathrm{BP}_{\mathrm{ND}}\right)$ were calculated using the simplified reference tissue method (SRTM) [22]. We also measured 
the DAT density availability at baseline and on day 14 of HAL treatment (follow-up). Pairs of $\mathrm{BP}_{\mathrm{ND}}$ maps were calculated relative to the cerebellum TAC, as documented in our previous characterization of this DAT ligand [20, 23].

\section{Brain slice electrophysiology study}

Veh- or HAL-treated C57BL6 mice were anaesthetized with sevoflurane, and brain slices $(250-300 \mu \mathrm{m})$ containing the midbrain or dorsal striatum were prepared. Whole-cell recordings of visualized neurons in the substantia nigra pars compacta $(\mathrm{SNc})$ were performed as previously described [17] (see details in the supplementary material).

\section{Neurophotonic study}

Primary hippocampal neurons were cultured and transfected with synapto-pHIuorin $(\mathrm{spH})$. Synaptic vesicle exocytosis in HAL and veh treatment groups was recorded using a fluorescence microscope as previously described [17]. Further details are described in the supplementary material.

\section{Statistical analyses}

Data analyses and a summary of the results are reported in the supplementary material.

\section{Results}

\section{Behavioral expression of antipsychotic treatment efficacy and failure}

We compared the efficacy of short- (2-6 days) and longterm (6-21 days) treatment with HAL $(0.5 \mathrm{mg} / \mathrm{kg} / \mathrm{d})$ or OLA $(10 \mathrm{mg} / \mathrm{kg} / \mathrm{d})$ in the inhibition of AMPH-induced hyperlocomotion and reversal of sensorimotor gating deficits in the PPI of the startle reflex test in rats. To prevent potential experimental biases related to the use of AMPH, we also measured the time-course of APD efficacy in a nonpharmacological model based on the hyperlocomotion induced by a TP. TP stimulates locomotor activity and promotes striatal dopamine release [24], which mimics the effects of AMPH. We found that short-term, but not chronic, HAL and OLA treatments at clinically relevant doses reversed the PPI deficit and blocked AMPH- and TPinduced hyperlocomotion, thus showing the efficacy of APD after short-term treatment and its declining efficacy with long-term treatment in all tests in rats (Fig. 1a-h). These results suggest that the loss of efficacy is a robust consequence of long-term APD treatment in animal models. No clear signs of abnormal motor behavior were observed during daily inspection throughout treatment periods.

\section{$D_{2}$ receptor binding and extracellular dopamine levels during antipsychotic treatment failure}

The occurrence of relapse during APD treatment of schizophrenia is attributed to an excessive potentiation of dopaminergic neurotransmission (dopamine supersensitivity) [25-28]. We hypothesized that concerted changes in receptor density [25, 29-31] and/or sensitivity [27, 32] may reduce APD occupancy at $\mathrm{D}_{2}$ receptors to below the therapeutic threshold. We measured the in vivo availability of striatal $\mathrm{D}_{2}$ receptors using positron emission tomography (PET) with $\left[{ }^{18} \mathrm{~F}\right]$ fallypride in rats undergoing 14 days HAL treatment, i.e., during the HAL loss of efficacy, to investigate this hypothesis. Animals were not challenged with AMPH or TP and the decreased efficacy of HAL in this group of animals was based on the results of the behavioral testing of independent subjects described above. We found that $\sim 69 \%$ of striatal $\mathrm{D}_{2}$ receptors were occupied by HAL (Fig. 2a), which indicates that the loss of HAL efficacy observed in the behavioral tests might occur despite constant and significant $\mathrm{D}_{2}$ receptor occupancy by HAL.

We also found that extracellular dopamine levels in rat $\mathrm{CPu}$ decreased with prolonged HAL and OLA treatments (Fig. 2b-g) and that individual dopamine levels correlated with the dopamine response to a TP stimulus (Fig. 2h, i). These results demonstrate that APD efficacy in the rat declines in concert with extracellular dopamine levels but not insufficient D2 receptor occupancy by APDs.

\section{Dopamine synthesis, release and clearance capacity during antipsychotic treatment efficacy and failure}

Extracellular dopamine concentrations are controlled via physiological mechanisms that establish a balance between release and re-uptake [33]. We investigated adaptations in the mechanisms of dopamine synthesis, release and clearance in relation to APD treatment efficacy and failure. We measured TH and DAT expression using Western blot analysis during HAL and OLA treatment. During treatment failure, we observed increased TH expression in the $\mathrm{CPu}$ (Supplementary Figure 1a, d) but not in the NAcc or PFC compared to vehicle (Supplementary Figure 1b, c, e, f). Also, APD did not alter the group mean of DAT expression in the $\mathrm{CPu}$, NAcc, or PFC (Supplementary Figure 2-3a, c, e). This result may erroneously suggest an absence of effect at this target. However, we detected strong inter-individual APD treatment-induced changes in DAT expression. Therefore, we described this variability by applying a standard procedure to calculate the mean absolute deviation (MAD) [34] using the following formula: individual data value group mean value $[x-(\Sigma x / n)]$. The value of each 

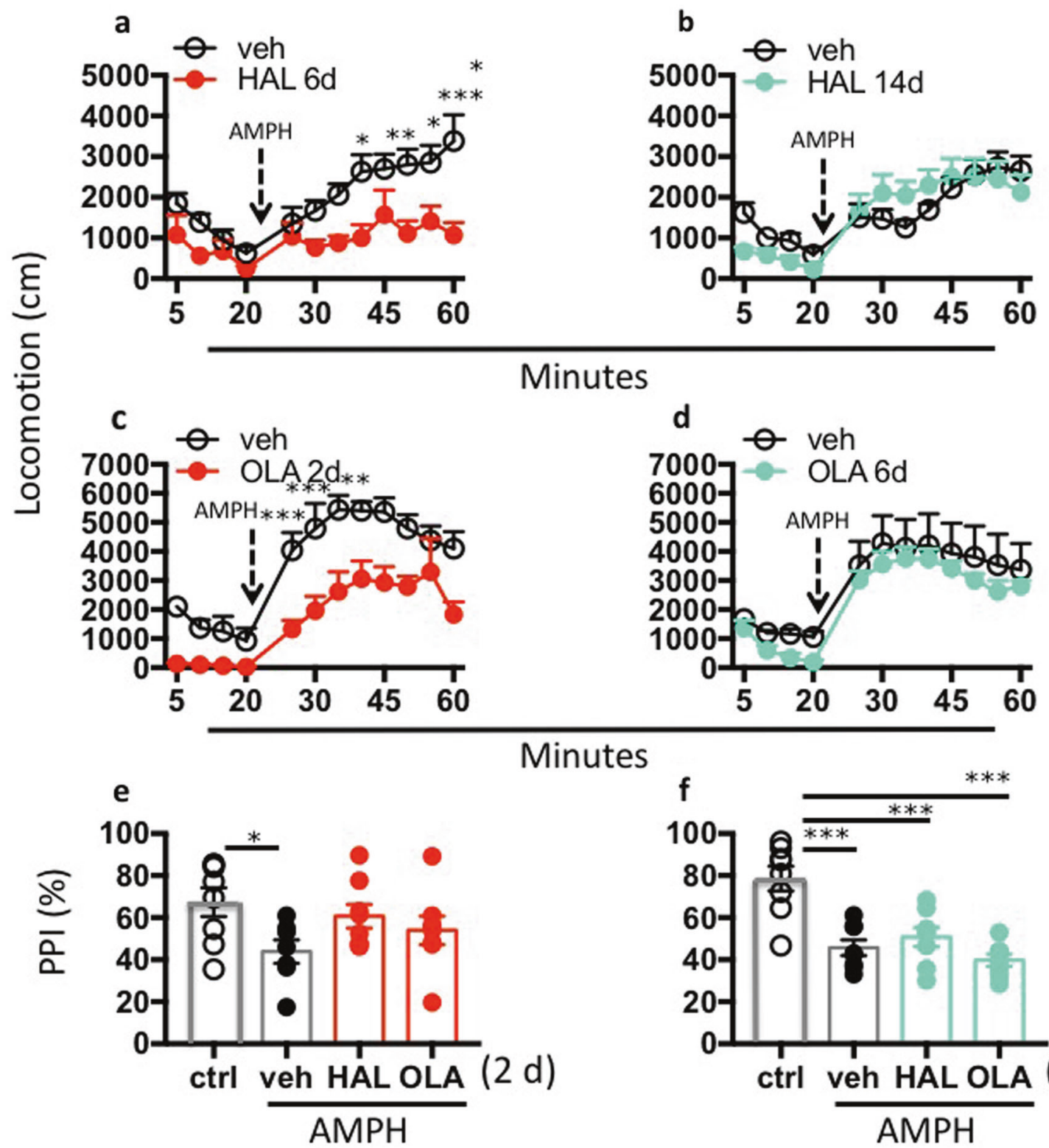

\section{Minutes}

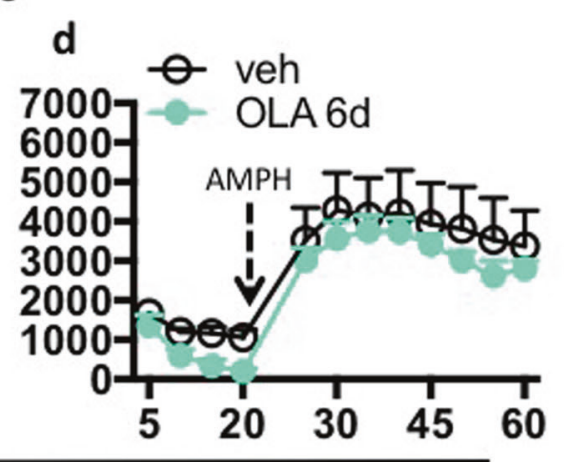

Minutes
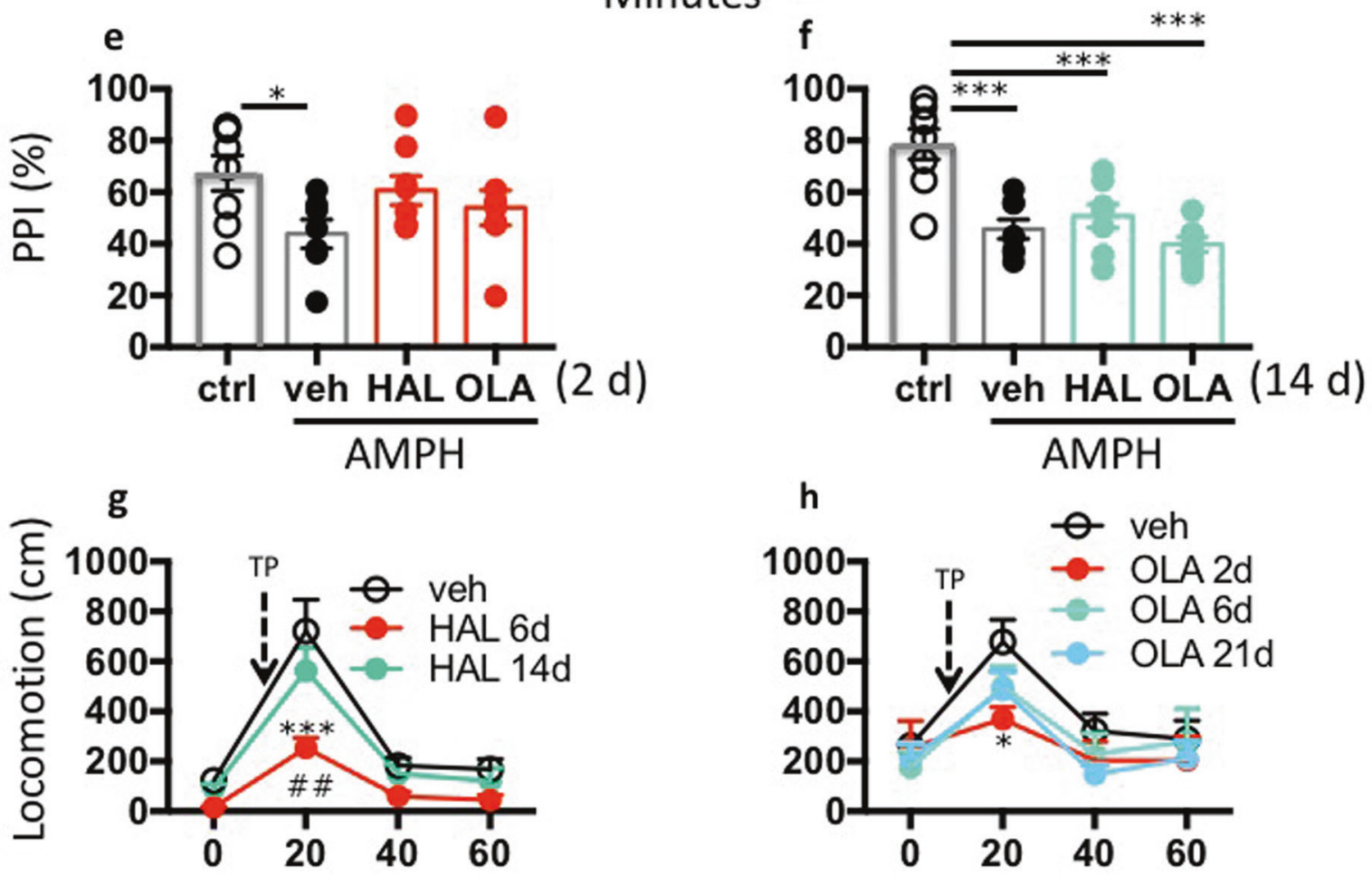

Minutes

individual DAT expression at a specific treatment point (i.e., 2, 6, 14, or 21 days) was subtracted from the group mean at the same treatment point.
We found inter-individual DAT changes in the $\mathrm{CPu}$ after 14 days of treatment with either APD (Supplementary Figure 2b and Fig. 3b) and in the NAcc with HAL treatment 
Fig. 1 Behavioral expression of antipsychotic treatment efficacy and failure. Short- and long-term efficacy of haloperidol (HAL) and olanzapine (OLA) in blocking the effects of amphetamine (AMPH) and tail pinch (TP) on behavioral activity. a, b HAL $(0.5 \mathrm{mg} / \mathrm{kg} / \mathrm{d})$ treatment for 6 days reduced AMPH-induced $(2 \mathrm{mg} / \mathrm{kg})$ hyperlocomotion $(P<0.01$, main effect), but no longer after 14 days treatment. $N=7 /$ group. c, d OLA $(10 \mathrm{mg} / \mathrm{kg} / \mathrm{d})$ treatment for 2 days reduced AMPH-induced $(2 \mathrm{mg} / \mathrm{kg})$ hyperlocomotion $(P<0.01$, main effect), but no longer after 6 days treatments. $N=5 /$ group. e, f HAL $(0.5 \mathrm{mg} /$ $\mathrm{kg} / \mathrm{d})$ or OLA $(10 \mathrm{mg} / \mathrm{kg} / \mathrm{d})$ prevented the PPI reduction induced by AMPH $(3 \mathrm{mg} / \mathrm{kg}$, vehicle (veh) vs. control (ctrl.), $P<0.05)$ after 2 days, but no longer after 14 days treatment (HAL: $P=0.0001$; OLA: $P<0.0001)$. g HAL $(0.5 \mathrm{mg} / \mathrm{kg} / \mathrm{d})$ treatment for 6 days reduced TP (20 min)-induced hyperlocomotion compared with veh $(P<0.0001)$, but no longer after 14 days treatment. $N=7-17 /$ group. h OLA $(10 \mathrm{mg} /$ $\mathrm{kg} / \mathrm{d})$ treatment for 2 days reduced TP $(20 \mathrm{~min})$-induced hyperlocomotion compared with veh $(P<0.05)$, but no longer after the continuous treatment. $N=5-20$ /group. All data are means \pm S.E.M $* P<$ $0.05, \quad * * P<0.01, \quad * * * P<0.001, \quad * * * * P<0.0001$. Statistical significance represents post hoc comparison when not specified

(Supplementary Figure 3d). HAL treatment also decreased NET expression in the NAcc (Supplementary Figure 4c). No other effects of HAL treatment on NET or SERT expression were observed in the $\mathrm{CPu}$, NAcc, or PFC compared with veh (Supplementary Figure 4, 5a-f). HAL and its metabolites directly interact with the DAT and other monoamine transporters [35]. Therefore, we further investigated the effect of APDs on DAT regulation. We estimated the putative coupling of striatal $\mathrm{TH}$ and DAT expression, which are coregulated [36]. We found no linear relationship between the TH and DAT expression levels in the control animals (Fig. 3d and Supplementary Figure 6a) or short-term HAL (Supplementary Figure 6b) or OLA treatments (Supplementary Figure 6c). However, long-term treatment with HAL (6-14 days) or OLA (21 days) progressively linearized the TH-DAT relationship, and higher TH levels were associated with increased DAT levels (Fig. 3a-c). This result suggests that APD treatment failure occurs in conjunction with the simultaneous increase in capacity for dopamine synthesis and uptake.

Next, we assessed whether changes in DAT levels occurred due to direct effects of APDs on mRNA expression. We measured DAT mRNA expression using polymerase chain reaction in the substantia nigra pars compacta $(\mathrm{SNc})$ and ventral tegmental area (VTA) at different HAL treatment times. We found that HAL suppressed DAT mRNA expression in the SNc and VTA after 2 days (Fig. 3e, f) compared with the control treatment. However, the inhibitory effect of HAL in the SNc gradually subsided during ongoing treatment (Fig. 3e). The suppression of DAT expression by HAL persisted until day 6 in the VTA (Fig. 3f). By day 14, DAT mRNA expression showed a modest trend toward regaining normal levels (Fig. 3f). These data suggest that the efficacy of HAL during shortterm treatment is associated with a robust suppression of
DAT mRNA expression in the SNc and VTA. In contrast, during APD failure, DAT mRNA expression was restored in the nigrostriatal system but not in the mesolimbic dopamine system. This effect suggests a dissociated mechanism in the brain, with dopaminergic projection systems serving to promote APD treatment failure, and the nigrostriatal system exhibiting the most striking changes.

To further investigate the role of the DAT in APD treatment failure, we measured the DAT density in vivo by microPET imaging using $\left[{ }^{18} \mathrm{~F}\right] \mathrm{FP}-\mathrm{CMT}$ in rats at baseline and after $14 \mathrm{~d}$ of HAL treatment. To verify treatment failure at that time, we also measured the TP-induced locomotor activation. We detected increased DAT availability (binding potential; $\mathrm{BP}_{\mathrm{ND}}$ ) in striatum at 14 days of HAL treatment (Fig. 3g, h) when treatment failure became evident as a disinhibition of TP-induced locomotion (Fig. $3 \mathrm{j}$ and supplementary Figure 7). DAT $\mathrm{BP}_{\mathrm{ND}}$ correlated with TP-induced locomotion (Fig. 3i), which demonstrates an association of APD efficacy and failure at the behavioral level with a dysregulation of dopamine clearance.

\section{Electrophysiological activity of dopaminergic neurons during antipsychotic treatment efficacy and failure}

Extracellular dopamine levels in nigrostriatal and mesolimbic areas also depend on tonic and phasic dopamine neuron activity $[37,38]$. Tonic activity is characterized by a spontaneous slow and irregular firing of dopamine neurons, and phasic activity is mediated by burst firing $[39,40]$. We measured the spontaneous firing, resistance, and capacitance of dopaminergic neurons from the $\mathrm{SNc}$ in brain slice preparations of mice after 6 or 14 days of HAL treatment (i.e., efficacy and failure conditions). Membrane input resistance and membrane capacitance of $\mathrm{SNc}$ dopamine neurons were unchanged after either HAL treatment duration (data not shown). Notably, treatment failure after 14 days of HAL treatment coincided with a significant reduction in the firing rate of spontaneously active neurons compared with the vehicle-treated group, but 6 days of HAL treatment did not alter the firing frequency (Fig. 4c). The slowed tonic firing after 14 days of HAL treatment may at least partially account for the reduced extracellular dopamine levels observed in the microdialysis experiments (Fig. 2e). Both drug regimens also affected silent dopamine neurons and shifted their resting membrane potentials to significantly more negative values (Fig. 4d). The HAL-associated hyperpolarization would impede the transition to tonic firing and impair the phasic mode of firing because only spontaneously active dopamine neurons can burst fire [39]. To examine the impact of the HAL-dampened firing frequency of SNc dopamine neurons on the postsynaptic 
a

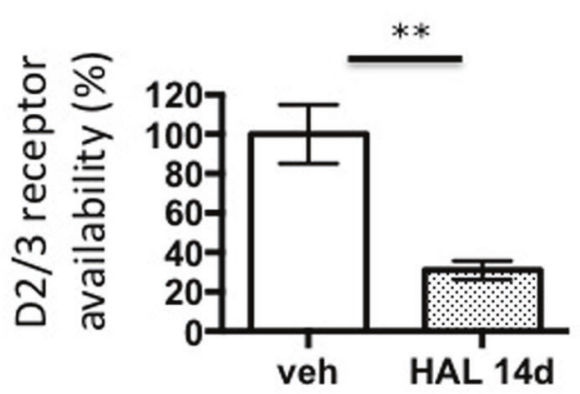

$\left[{ }^{18} \mathrm{~F}\right]$ fallypride
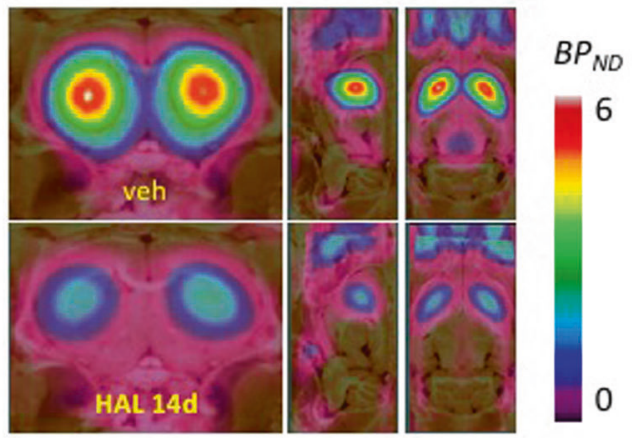

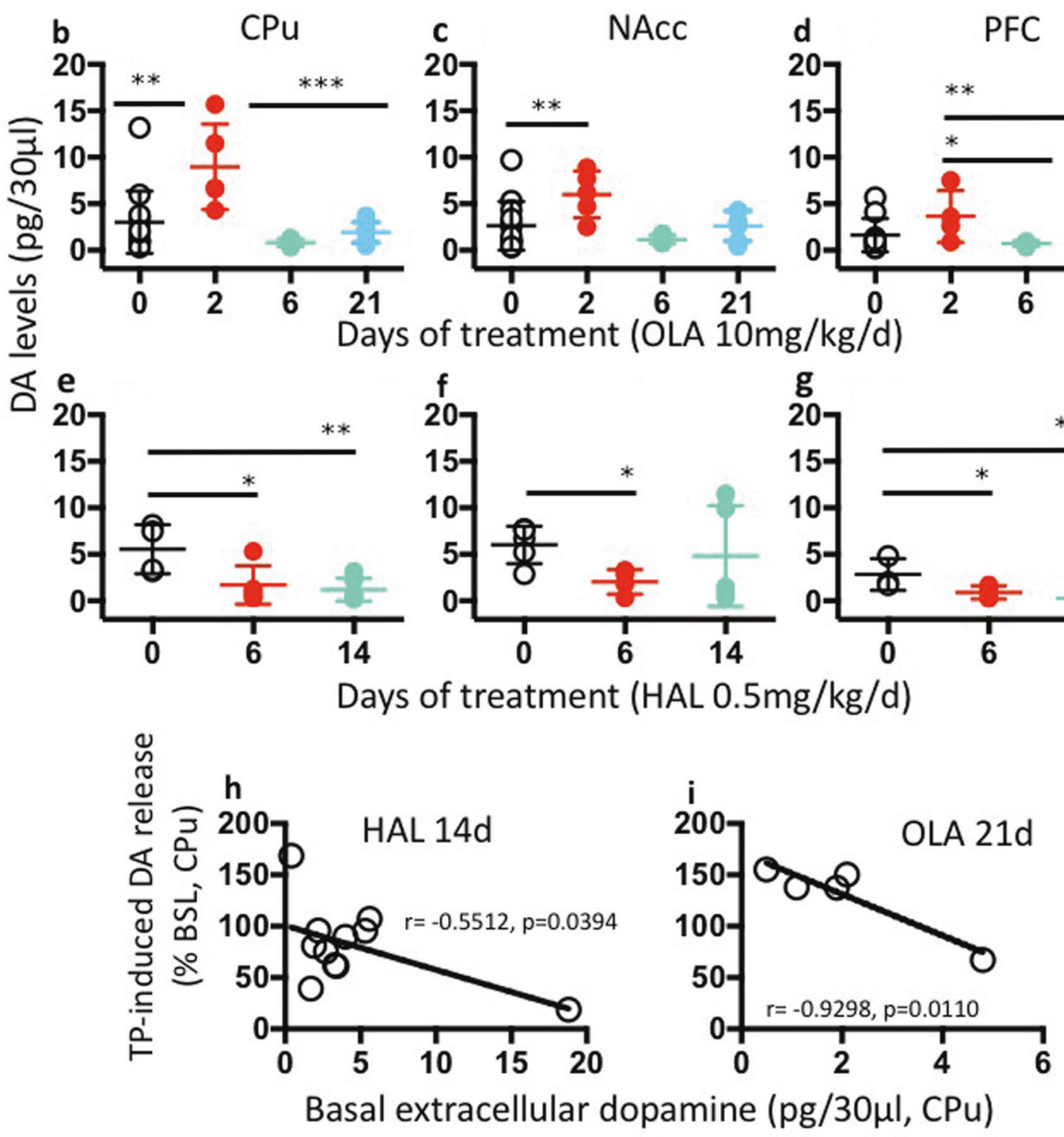

side, we monitored the neuronal population responses in $\mathrm{CPu}$, the main projection target. Local electrical stimulation in the $\mathrm{CPu}$ evoked responses that consisted of a biphasic field potential, with an early axonal component (fibre volley) and a late synaptic component. The latter component predominantly arose from excitatory 
Fig. 2 Dopamine $\mathrm{D}_{2}$ receptor binding and extracellular dopamine levels during antipsychotic treatment failure. a Mean parametric maps in the coronal, left sagittal, and horizontal planes of the binding potential $\left(\mathrm{BP}_{\mathrm{ND}}\right)$ of the $\mathrm{D}_{2}$ receptor radioligand $\left[{ }^{18} \mathrm{~F}\right]$ fallypride determined by PET imaging in animals treated with vehicle (upper row; veh) or with haloperidol (HAL) for 14 days (lower row, HAL 14d). The images represent the mean of four separate animals in each group. The mean $D_{2 / 3}$ receptor occupancy under HAL treatment was $69 \pm$ $15 \%$ ( $n=4, P<0.001$, unpaired $t$-test Fig. $2 \mathrm{a}$ ), as calculated relative to the mean $\mathrm{BP}_{\mathrm{ND}}$ in four vehicle control animals (occupancy $=[\mathrm{BP}$ (veh)-BP(HAL 14d)]/BP(veh) $\times 100 \%$ ). The parametric maps were spatially normalized to a standard histological atlas of rat brain. b-g Changes in extracellular dopamine in caudate-putamen $(\mathrm{CPu})$, nucleus accumbens (NAcc), and pre-frontal cortex (PFC) after continuous treatment with olanzapine (OLA) or HAL. b OLA increased extracellular dopamine levels in the $\mathrm{CPu}$ after 2 days treatment compared to control (day 0$)(P=0.001)$ and to all other treatment periods $(P<0.001)$. c OLA increased extracellular dopamine levels in the NAcc after 2 days treatment compared to control (day 0$)(P<0.01)$. d In PFC, 2 days OLA treatment increased dopamine levels compared with groups treated for 6 and 21 days $(P<0.05)$, but not compared with control (day 0). $N=4-14$ /group. e HAL decreased dopamine levels in $\mathrm{CPu}$ after 6 days $(P<0.05)$ and after 14 days $(P<0.01)$ compared with control (day 0 ). $N=4-6$ /group. f HAL decreased dopamine levels in PFC after 6 days $(P<0.05)$ and after 14 days $(P<$ 0.01 ) compared with control (day 0$) . N=3-4$ /group. g HAL decreased dopamine levels in NAcc after 6 days $(P<0.01)$ as detected post doc using a $t$-test, but not after 14 days. $N=4-5$ /group. Data are means \pm S.D. $* P<0.05, * * P<0.01, * * * P<0.001$. Statistical significance represents post hoc comparison when not specified. h-i Relationship between extracellular dopamine levels at the baseline in the $\mathrm{CPu}(X$ axis) and dopamine release in the $\mathrm{CPu}(Y$-axis) in response to tailpinch (TP), expressed in percentage change of the baseline. $\mathbf{h}$ The reduced dopamine levels provoked by 14 days HAL treatment correlated with the dopamine release stimulated by TP (pearson $r=-0.5512, P<0.05) . N=11$ group. i The reduced dopamine levels driven by 21 days treatment with OLA correlated with the dopamine output stimulated by TP (pearson $r=-0.9298, P<0.05$ ). $N=5 /$ group

postsynaptic currents, as indicated by their suppression by the AMPA receptor antagonist, CNQX (Fig. 4e). The effect of HAL on the input-output relationship of synaptic field responses (stimulation intensity $50-400 \mu \mathrm{A}$ ) revealed a striking dependence on treatment duration, with a reduction after 6 days and a potentiation after 14 days of HAL treatment (Fig. 4f). This shift may reflect a reversal of drug action from therapeutic to non-effective. To determine the drug's effect on synaptic transmission during the repetitive activation of presynaptic fibres, we delivered a train of 40 stimuli at $25 \mathrm{~Hz}$. This stimulation protocol produced an initial enhancement of synaptic field potentials followed by a rapid decline, which was significantly accelerated in slices from 6 days HAL and 14 days HAL mice (Fig. $4 \mathrm{~g}$ ). Consistent with our previous findings, which indicated that the release of an intravesicular pool of accumulated APDs dampens synaptic transmission by blocking presynaptic $\mathrm{Na}^{+}$channels [17], we found that in the same stimulation protocol, the fibre volley amplitudes declined during prolonged HAL administration (Fig. 4h).

\section{Dopamine release mechanisms during antipsychotic treatment efficacy and failure}

Active and spontaneous dopamine release occurs via vesicular exocytosis at active zones associated with $\mathrm{Ca}^{2+}$ channels [41-44], and APDs target this mechanism $[17,45]$. We previously observed that APDs accumulate in the synaptic vesicles of cultured hippocampal neurons via an acidic trapping mechanism and inhibit $\mathrm{Na}^{+}$channels upon release. This inhibition leads to the feedback inhibition of $\mathrm{Ca}^{2+}$ influx and reduces neurotransmitter release [17]. We investigated whether longer APD treatment regimens that mimic APD efficacy and failure would affect dopamine exocytosis. We transfected cultures of hippocampal neurons, which should exhibit similar vesicular release mechanisms to dopamine neurons [46], from juvenile rats with synapto-pHIuorin $(\mathrm{spH})$ and recorded synaptic vesicle exocytosis using real-time fluorescence microscopy after $1 \mathrm{~h}, 6$ days or 14 days of treatment with HAL or vehicle control in culture [47]. We measured the sizes of two distinct vesicle pools, the readily releasable pool (RRP) and the recycling pool (RP) [48]. The RRP defines the neurotransmitter pool that is immediately available for release, and RP is related to the replenishment of the RRP during neuronal activity. We found that HAL suppressed the RRP within $1 \mathrm{~h}$ of treatment, potentiated suppression after 6 days of HAL treatment, and enhancement of RRP after 14 days of HAL treatment (Fig. $5 \mathrm{~g}$ ). RP was significantly reduced after 6 days of HAL treatment but was enlarged after 14 days of HAL treatment (Fig. 5f). RRP and RP reflect synaptic efficacy under physiological conditions. Therefore, our data suggest that the physiological mechanisms of exocytosis-mediated neurotransmitter release are modulated in opposing directions after HAL treatment during APD efficacy and failure. The present data extend our previous observation that APDs inhibited vesicle release during efficacious treatment, but this effect was reversed with prolonged HAL treatment. Therefore, treatment failure is associated with enhanced dopamine exocytosis.

The exocytosis inhibition in cultured neurons acutely treated with HAL may be attributed to the ability of HAL to inhibit $\mathrm{Na}^{+}$, rather than $\mathrm{Ca}^{2+}$, channels because $\mathrm{K}^{+}$treatment induced exocytosis in the presence of APDs [17]. To evaluate whether the same mechanism occurs both in vivo and after treatment with clinically equivalent doses, we measured the extracellular dopamine levels in the $\mathrm{CPu}$ and in NAcc in freely behaving rats. Local dopamine release was stimulated using reverse dialysis with $100 \mathrm{mM} \mathrm{K}^{+}$[17] in animals treated for 6 or 14 days with HAL or veh. The $6 \mathrm{~d}$ $\mathrm{HAL}$ treatment blocked the $\mathrm{K}^{+}$-induced dopamine release in the $\mathrm{CPu}$ (Fig. 5h) and NAcc (Fig. 5i) and prevented $\mathrm{K}^{+}$-induced hyperlocomotion (Fig. 5j). These effects were reversed after 14 days of HAL treatment (Fig. 5h-l), 

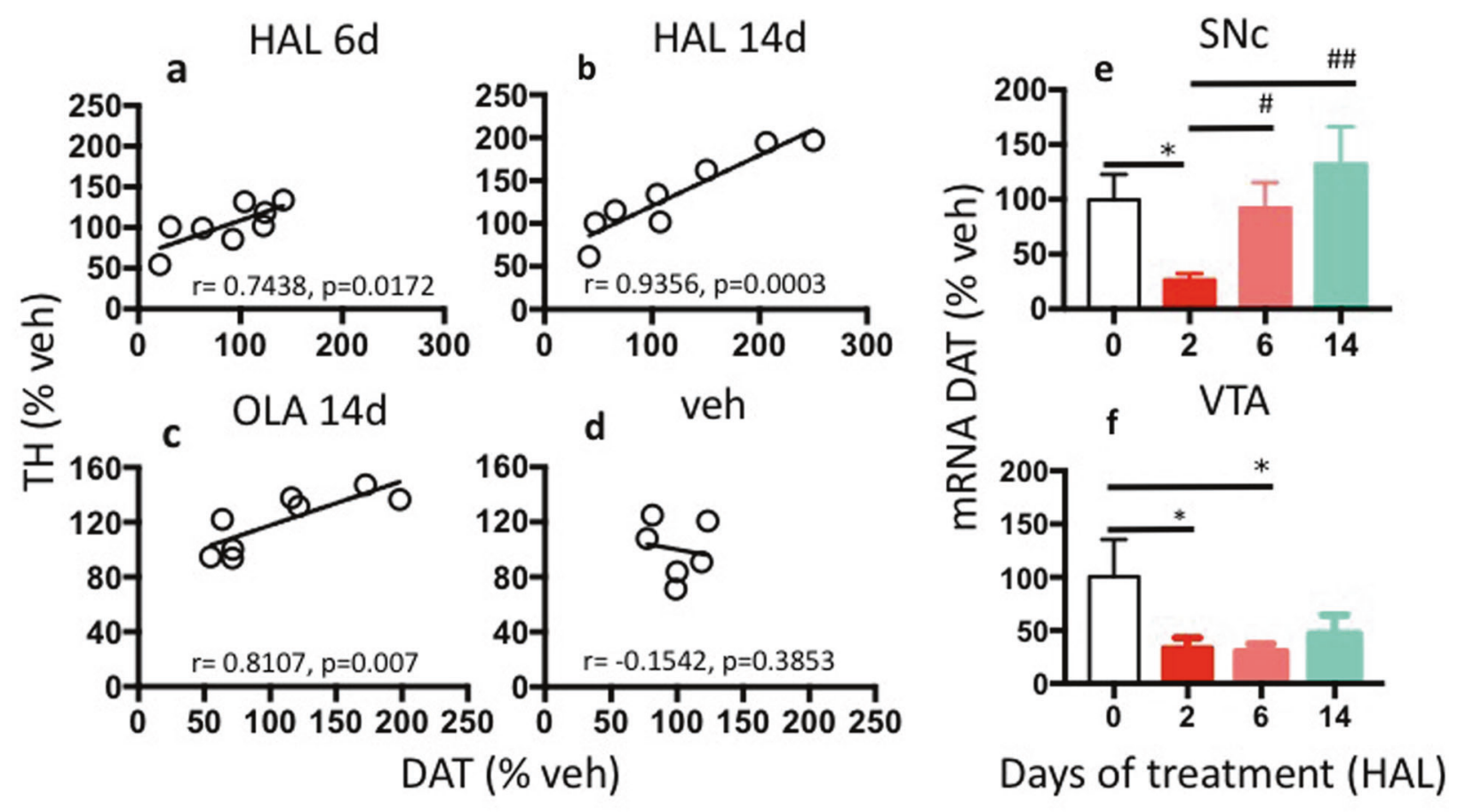

g

[ $\left.{ }^{18} \mathrm{~F}\right] \mathrm{FP}-\mathrm{CMT}$
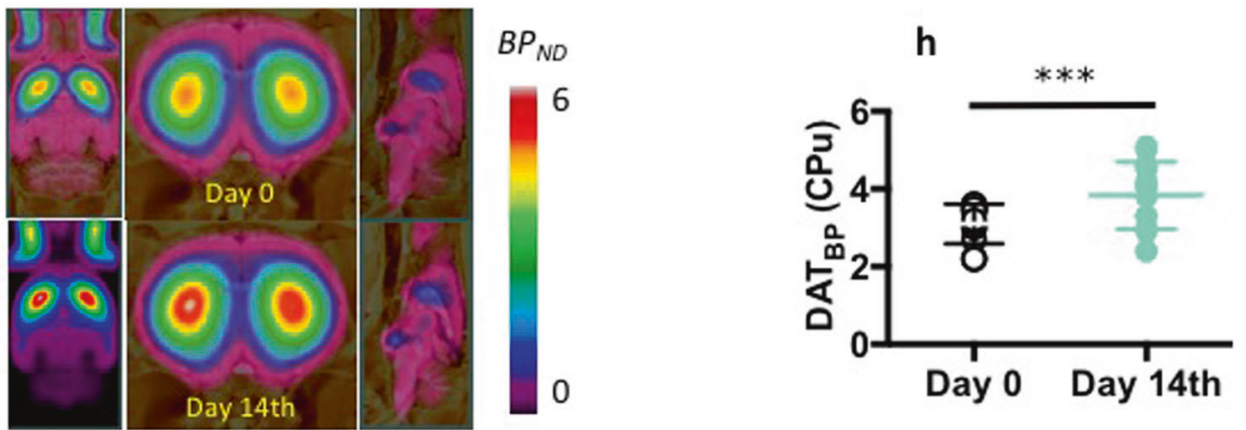

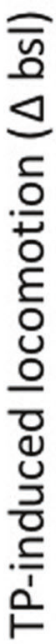

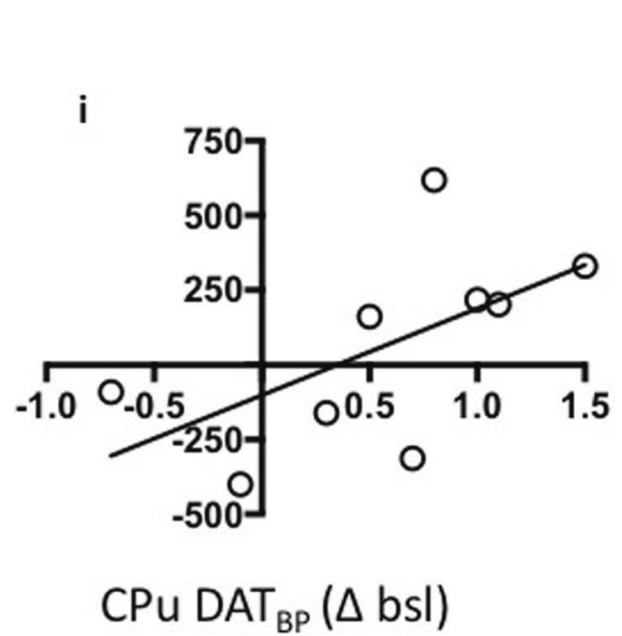

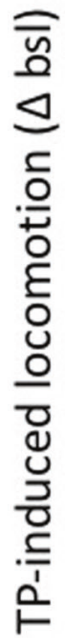

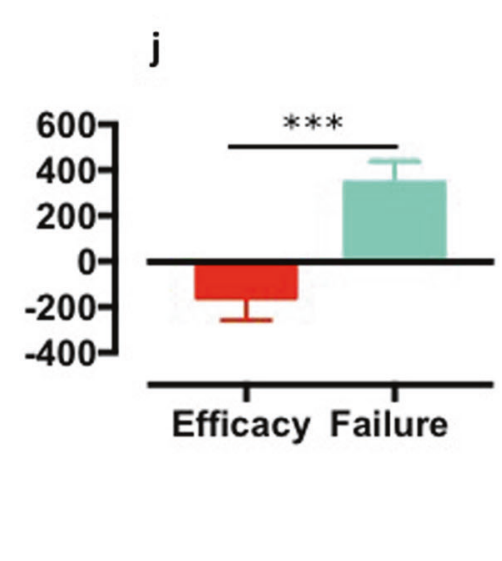


Fig. 3 Dopamine synthesis, release and clearance capacity during antipsychotic treatment failure. a, b The expression of dopamine transporter (DAT) and tyrosine hydroxylase $(\mathrm{TH})$ is coregulated after 6 days (Pearson $r=0.7438, P<0.05$ ) and 14 days (Pearson $r=0.9356$ $P<0.001)$ HAL treatment. $N=8$ /group. c The expression of DAT and $\mathrm{TH}$ is coregulated by 21 days olanzapine (OLA) treatment (Pearson $r=0.8107, P<0.01$ ), but not by the treatment with vehicle (veh) (d). $N=8$ /group. e,f Changes in DAT mRNA expression in the substantia nigra (SNc) and in the ventral tegmental area (VTA) after continuous treatment with haloperidol (HAL). HAL treatment for 2 days decreased DAT mRNA expression in the SNc compared with veh $(P<0.05$, main effect) and to $6(P<0.05)$ and $14(P<0.01)$ days HAL. $N=7-8$ /group. Data are means \pm S.E.M $(* P<0.05-$ vs. veh, ${ }^{\# \#} P<0.01$ - vs. 2 d HAL treatment). f HAL treatment for 2 and 6 days decreased DAT mRNA expression in the VTA compared to veh $(p<$ $0.05)$. This inhibitory effect vanished after 14 days. $N=7-8 /$ group. All data are means \pm S.E.M $(* P<0.05, * * P<0.01, * * * P<0.001)$. g DAT density (expressed as mean parametric maps of binding potential $\left.\left(\mathrm{BP}_{\mathrm{ND}}\right)\right)$ in animals scanned first at baseline and after 14 days HAL treatment, as determined by PET imaging with $\left[{ }^{18} \mathrm{~F}\right] \mathrm{FP}-\mathrm{CMT}$. h HAL treatment for 14 days increased the mean group of $\mathrm{DAT}_{\mathrm{BP}}$ in the caudate-putamen $(\mathrm{CPu})$ compared with baseline $(P<0.001)$. $N=16$ /group. Data are means \pm S.D. i Relationship between $\mathrm{DAT}_{\mathrm{BP}}$ changes (calculated as delta between follow-up and baseline) in the $\mathrm{CPu}$ and hyperlocomotion response to tail pinch (TP) (calculated as delta between stimulation and baseline) (pearson $r=0.7167$, $P<0.05) . \quad N=9$ /group. Data are means \pm S.D. j Animals with a $\mathrm{DAT}_{\mathrm{BP}}<0.8$ were experiencing treatment efficacy compared with the subgroup with a $\mathrm{DAT}_{\mathrm{BP}}>0.8$ who were instead prone to antipsychotic treatment failure $(P<0.01) . N=9$ /group. Data are means \pm S.E.M. $(* P<0.05, * * P<0.01, * * * P<0.001)$. Statistical significance represents post hoc comparison when not specified

consistent with the effects of APDs on vesicle pool parameters because HAL treatment reduced stimulated dopamine release in the brain during the treatment efficacy phase but not during treatment failure.

\section{Reversal of antipsychotic treatment failure}

APD treatment failure and the generally variable responses to APD treatment are major problems in schizophrenia pharmacotherapy. Having identified the mechanisms that may mediate unfavourable outcomes, we next derived a potential intervention to reverse APD treatment failure and reinstate APD efficacy in behavioral and neurophysiological terms. The present data suggest that if reduced tonic dopamine transmission in the striatum is relevant to the loss of APD efficacy, then a moderate stimulation of tonic dopamine release may restore APD efficacy. We tested this hypothesis in microdialysis studies in freely moving rats. One study measured the extracellular dopamine levels in 14 days HAL-treated and control animals and their locomotor response to TP. We also performed an identical study with an additional treatment of both animal groups with the DAT blocker GBR12909 (10 mg/kg, i.p.) after measuring dopamine at baseline and before recording the TP-induced hyperlocomotion. As observed previously, HAL reduced the extracellular dopamine levels after 14 days of treatment compared with the control treatment (Fig. 6a) in association with the failure of HAL to inhibit the TP-induced hyperlocomotion (Fig. 6b). We replicated the finding of reduced extracellular dopamine during prolonged HAL treatment (Fig. 6c). The co-administration of the DAT blocker moderately increased extracellular dopamine levels in 14 days HAL-treated animals but not in the control group, which reduced the group differences in dopamine levels (Fig. 6d). The combination of the acute DAT blocker and 14 days HAL treatments resulted in a net inhibition of TP-induced hyperlocomotion (Fig. 6e). Therefore, GBR12909 rescued $\sim 40 \%$ of the inhibitory effects of HAL (Fig. 6f). This behavioral effect was not confounded by stereotypies, which may occur when GBR12909 or other psychostimulants are administered after chronic APD regimens [49]. The animals in our conditions exhibited a "fluid" execution of locomotor activity that was not compromised by stereotypes, which would otherwise rigidly dominate the overall behavioral performance. The dose of GBR12909 only modestly increased extracellular dopamine levels (Fig. 6d). These results clearly suggest that a slight potentiation of tonic dopamine levels rescued APD treatment outcomes, which supports the hypothesis that DAT blockers may be used clinically as an adjunct treatment to reverse APD treatment failure.

We also investigated whether the mechanism of this protective effect was mediated in the $\mathrm{CPu}$. We administered GBR12909 (G, $20 \mu \mathrm{g} / \mu \mathrm{l} / \mathrm{side}$ ) or vehicle directly into the $\mathrm{CPu}$ of rats with 14 days of HAL treatment. Intracerebral vehicle infusion did not alter the usual loss of locomotor inhibition in HAL-treated rats (Fig. 6g), which is indicative of treatment failure. However, the infusion of GBR12909 to the $\mathrm{CPu}$ (intra-cuadate, i.c.) inhibited the TP-induced locomotion in 14 days HAL-treated animals (Fig. 6g), which mimicked the behavioral response that is normally observed during HAL treatment efficacy. These data strongly suggest that the dopaminergic innervation of the $\mathrm{CPu}$ is a critical site for a pharmacological reversal of APD treatment failure.

\section{Discussion}

The present findings elucidate crucial mechanisms of APD therapeutic action and failure and provide a new strategy for failure reversal. First, our model reproduced APD action and failure using clinically relevant APD dosing and treatment regimens. Second, the mechanism underlying APD efficacy was primarily characterized by preserved or increased extracellular dopamine levels in the $\mathrm{CPu}$ in association with reduced DAT mRNA expression and relatively preserved expression of $\mathrm{TH}$ and of membrane DAT protein. Third, the physiological pattern of APD 
a SNc dopaminergic neurons

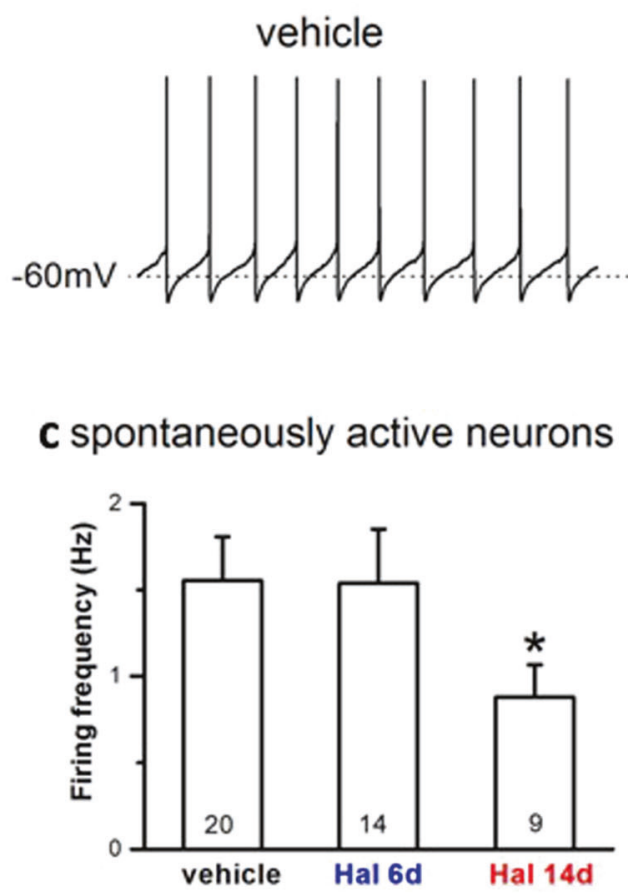

e CPu field potentials
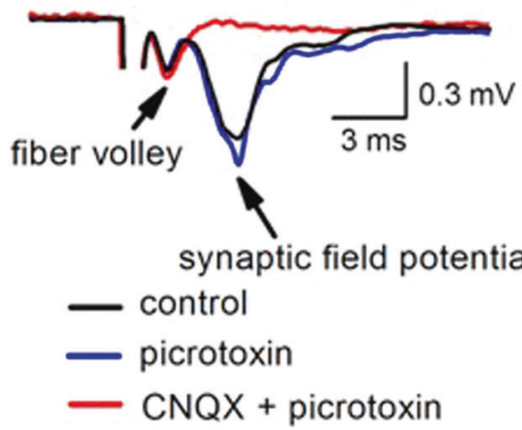

g

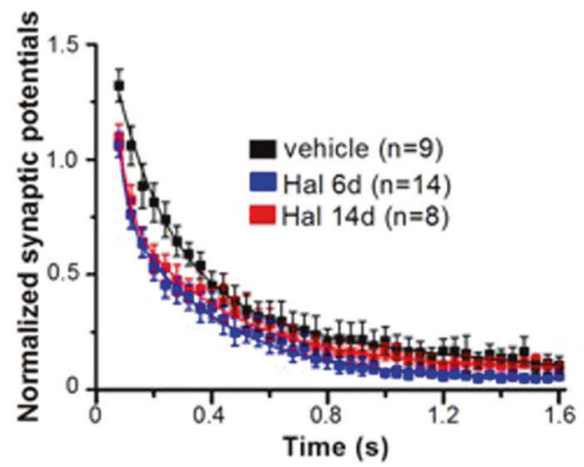

b Haloperidol 14d

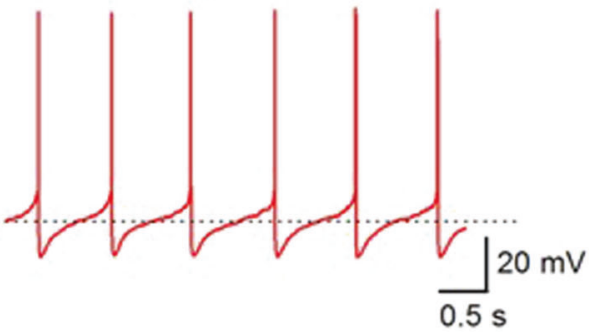

d silent neurons

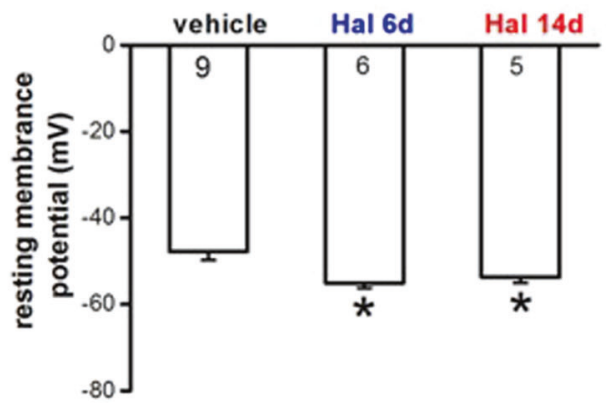

f

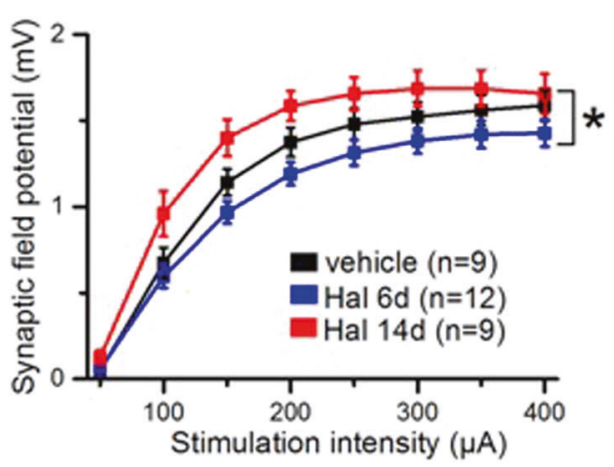

h

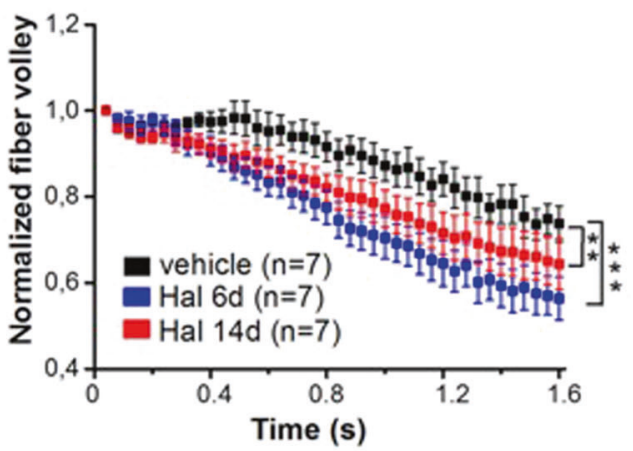

size). The physiological changes underlying APDs efficacy were substantially reversed during APD failure. Specifically, we found that (1) baseline extracellular dopamine 
Fig. 4 Electrophysiological activity of dopaminergic neurons during antipsychotic treatment failure. Chronic haloperidol (HAL) inhibits substantia nigra pars compacta $(\mathrm{SNc})$ dopaminergic neurons (a-d) and changes synaptic transmission in the caudate-putamen $(\mathrm{CPu})$ (e-h). a-b Representative voltage traces recorded from mouse brain slices show the regular discharges of spontaneously active dopaminergic neurons from a vehicle (veh)-treated (a) and a 14-day HALtreated (b), HAL 14d) mouse, respectively. c, d Histograms summarize HAL-induced reduction in firing rate (HAL 6d $P=0.97$, HAL 14d $P=0.040$; vs. veh) and shift of resting membrane potentials in $\mathrm{SNc}$ dopaminergic neurons (HAL 6d $P=0.047$, HAL $14 \mathrm{~d} P=0.020$; vs. veh). e Superimposed traces recorded from a vehicle-treated mouse slice illustrate the biphasic field potentials (at stimulation intensity of $100 \mu \mathrm{A}$ ) in the $\mathrm{CPu}$, with an early axonal component (fiber volley) and a late synaptic component. Stimulation artifact is truncated. The $\mathrm{GABA}_{\mathrm{A}}$ receptor antagonist picrotoxin $(100 \mu \mathrm{M})$ and AMPA receptor antagonist CNQX $(20 \mu \mathrm{M})$ were used to determine nature of synaptic field potentials. f Input-output curves of synaptic field potentials were plotted to show the time-dependent effect of HAL on $\mathrm{CPu}$ synaptic transmission (treatment: $P=0.012$; time: $P<0.0001$; interaction: $P=$ 0.112; two-way ANOVA). $g$ The use-dependent decline of $\mathrm{CPu}$ synaptic responses during 40 stimuli at $25 \mathrm{~Hz}$ was facilitated by $\mathrm{HAL}$ treatment. Decay time constant in vehicle group $(n=9,0.31 \pm 0.05 \mathrm{~s})$ was significantly longer than in HAL $6 \mathrm{~d}(n=14,0.18 \pm 0.02 \mathrm{~s}, P=$ $0.030)$ and HAL $14 \mathrm{~d}(n=9,0.19 \pm 0.02 \mathrm{~s}, P=0.048)$. Synaptic responses were normalized to their amplitudes before the train. h Chronic HAL reduced the isolated axonal activity during train stimuli. In this set of experiments, fiber volleys were recorded in low calcium solution $(0.2 \mathrm{mM})$ with antagonists for glutamatergic and GABAergic receptors. Amplitudes of fiber volleys were normalized to their amplitudes before train. All data are means \pm S.E.M. $(* P<0.05)$. Sample numbers in each group were indicated in the columns or as insets

levels in the $\mathrm{CPu}$ were suppressed, (2) the initial inhibition converted into an upregulation of both DAT mRNA and membrane protein, and (3) neurotransmitter synthesis and release mechanisms were potentiated. However, we also found that at a time interval when we recorded APD failure, i.e., after 14 days of treatment, $\mathrm{D}_{2}$ receptor occupancy to $\left[{ }^{18} \mathrm{~F}\right]$ fallypride PET was in a "therapeutic range," as measured in an independent group of animals. These results suggest that mechanisms beyond $\mathrm{D}_{2}$ receptor occupancy and depolarization blockade are involved in APD treatment efficacy and failure. Our data suggest a specific role of the DAT in the mediation of APD treatment efficacy and APD failure. Therefore, dysregulated dopamine uptake, which follows the initial suppression of DAT expression, leads to decreased extracellular dopamine levels. Informed by these observations, we reinstated the behavioral parameters of APD efficacy using pharmacological blockade of the DAT. Therefore, human patients experiencing relapse upon chronic treatment with APDs may experience restored therapeutic efficacy when APD treatment is combined with DAT blockers, such as Vanoxerine (GBR12909) [50], which have the advantage of evoking only a moderate increase in extracellular dopamine, despite acting at a higher binding affinity than cocaine, thus perhaps lowering the risk of abuse [51, 52].
Conflicting evidence exists for the role of DAT in schizophrenia [53, 54], with most of the studies reporting no change [55] or a decrease in DAT density in terminal areas of dopaminergic neurons, especially in patients treated with APDs [55-58]. These discrepancies could be attributed to independent but overlapping factors. For example, the choice of testing drug-naïve patients can itself be a source of variability since genetic heterogeneity drives DAT expression [59]. Based on our results, DAT density alterations can be driven solely by APD treatment (Fig. $3 \mathrm{~h}, \mathrm{j}$ and supplementary Figures $2 b$ and $3 b$ ). The age of patients is an additional factor that might introduce variability and limit the detection of DAT density changes in human studies. PET imaging studies have shown significant differences in DAT density between $<40$ vs. $>40$ years old healthy individuals [60]. Most likely, DAT density will not change at the same rate on a particular time point in all individuals. Rather, it will fall below some threshold at a definite age, e.g., $<40$ years, for each individual. Therefore, a considerable variability in DAT availability might even exist within the same age group.

Furthermore, it has been suggested that brain aging as distinct from chronological age of the organism can alter DAT density via deterioration of white matter integrity and cardiovascular risk factors accounted for the underlying shared mechanism [61]. Notably, white matter integrity is an important moderator of the initial APD response at the start of the treatment [62]. Continued APD treatment for 12 weeks can cause subtle losses of white matter integrity in first-episode psychosis [63].

Additional factors that may account for the variability in detecting DAT density changes in schizophrenia are ascribable to the dynamic of the DAT expression. DAT levels adapt in line with dopamine transmission, decreasing or increasing depending on whether dopamine release is low or high [64]. During acute psychosis, when dopamine levels are expected to be high, DAT levels might be higher than after the psychotic episodes (i.e., recovery). Our findings are in line with those studies reporting on the dynamicity underlying DAT density changes. We demonstrated a considerable suppression of DAT mRNA expression during the initial stages of HAL treatment (after 2 days), which gradually reversed within 2 weeks in the SNc, but remained substantially suppressed in the VTA during the same time period. These changes in DAT mRNA expression reflected corresponding changes in DAT protein expression at the plasma membrane. Furthermore, the HAL efficacy in behavioral tests clearly decreased after the first week of treatment when most of the DAT adaptations had already taken place. This plasticity would have been missed if measurements had been performed only on day 6 or later, i.e., when antipsychotic efficacy was already abolished. Besides indicating critical time points when putative DAT 

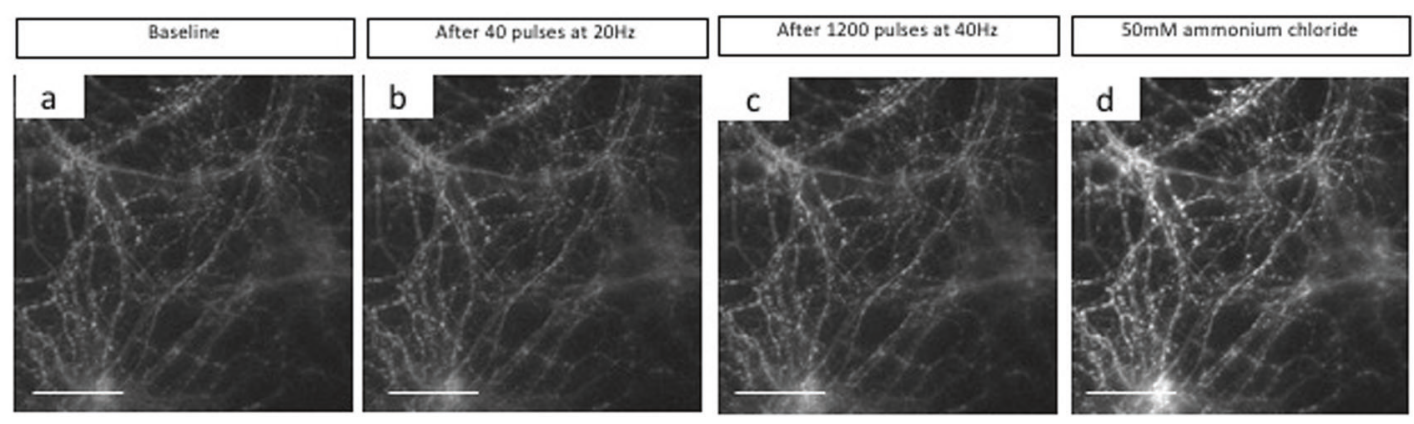

e

f

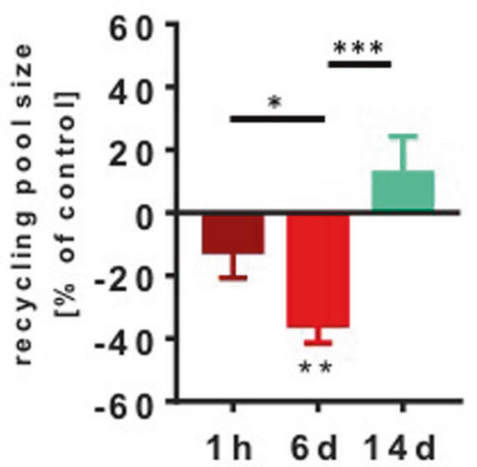

Readily releasable pool

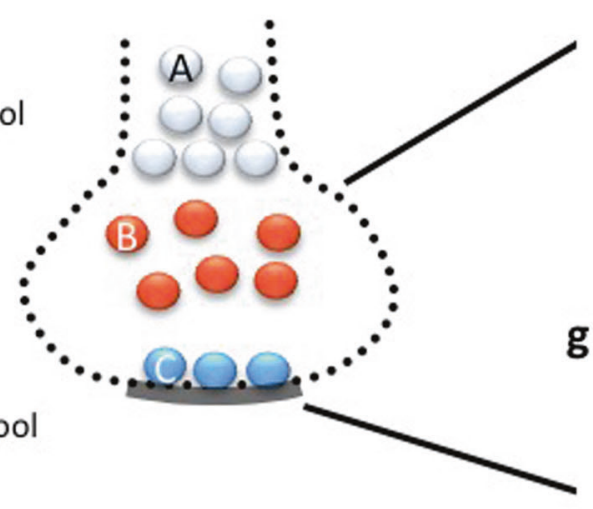

$\vartheta$ veh

g
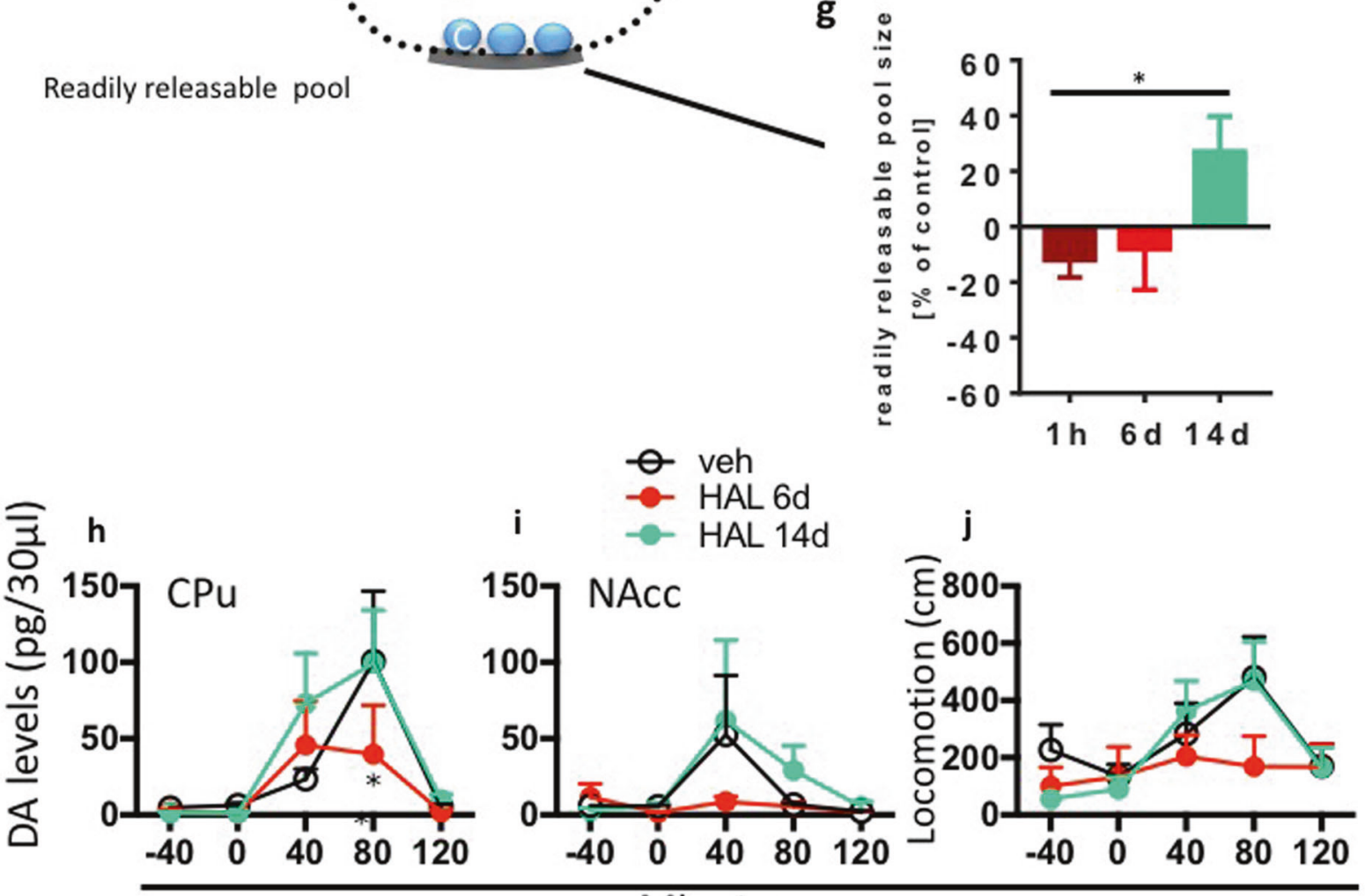

\section{Minutes}

density changes driven by the APD treatment may be detected, our data strongly suggest that the early inhibition followed by a normalization or, in some cases, an upregulation of DAT expression in striatal tissue constitutes a fundamental component of HAL efficacy and failure, respectively. Accordingly, a previous rat microPET study 
Fig. 5 Dopamine release mechanisms during antipsychotic treatment efficacy and failure. a-d Exemplary raw recording of neurons during vesicle pool size measurement. Cells were transfected with synaptopHluorin and treated with $80 \mathrm{nM}$ haloperidol (HAL) prior to the experiment. Cells were perfused with imaging buffer containing $80 \mathrm{nM}$ HAL during the entire recording as well; a Raw image showing baseline fluorescence; b Raw image showing fluorescence after electrical stimulation with 40 pulses at $20 \mathrm{~Hz}$, which corresponds to the readily releasable pool vesicles being fluorescent; c Raw image showing fluorescence after further electrical stimulation with 1200 pulses at $40 \mathrm{~Hz}$, which corresponds to the recycling pool vesicles being fluorescent additionally; d Raw image showing fluorescence during perfusion with imaging buffer containing additional $50 \mathrm{mM}$ ammonium chloride, which corresponds to all synaptic vesicles being fluorescent; Scale bar $=25 \mu \mathrm{m}$. e Schematic drawing of the different synaptic vesicle pools in a synaptic bouton: resting pool, recycling pool and readily releasable pool docked to the active zone. $\mathbf{f}$ Effect of HAL in vesicle recycling pool size in hippocampal cells after $1 \mathrm{~h}(P=$ $0.0132, n=9$ recordings $)$ or $6(P=0.0052, n=14$ recordings $)$ and 14 days $(P=0.0009, n=21$ recordings $)$ treatment compared with vehicle (DMSO, control group). g Effect of HAL in vesicle readily releasable pool size in hippocampal cells compared with controls $(P=$ 0.0136, $n=21$ recordings). h-i HAL $(0.5 \mathrm{mg} / \mathrm{kg} / \mathrm{d})$ treatment for 6 , but not for 14 days, reduced potassium $\left(\mathrm{K}^{+}\right)$-induced $(100 \mathrm{mM}$, infused via reversed dialysis) dopamine release in the caudate-putamen $(\mathrm{CPu})(P<0.0001$, main effect) and in the nucleus accumbens (NAcc) $(P<0.05)$ compared with baseline $n=4-6 /$ group. 1 HAL $(0.5 \mathrm{mg} / \mathrm{kg} /$ d) treatment for 6 , but not for 14 days reduced $\mathrm{K}^{+}$-induced $(100 \mathrm{mM})$ hyperlocomotion compared to baseline $(P<0.05$, main effect). $N=4-13$ /group. All data are means \pm S.E.M $* P<0.05, * * P<0.01$, $* * * P<0.001$. Statistical significance represents post hoc comparison when not specified

using $\left[{ }^{123} \mathrm{I}\right]$-FP-CIT has shown reduced DAT binding only minutes after acute HAL injection [65]. Based on our data, the HAL-driven reduction in DAT binding may occur either directly through reduction of DAT density in the plasma membrane or via suppressed DAT mRNA expression at very early treatment stages. Alternatively, availability changes may reflect radioligand displacement by increased dopamine levels due to the inhibition of DAT expression. It is also be possible that sustained brain concentrations of HAL resulting from the treatment with osmotic pumps may block the DAT transporter directly, thus causing an increase in dopamine levels. Studies using neuronal cell culture have shown the likelihood of this possibility [35]. Additionally, the increased dopaminergic tone, driven by the initial HAL treatment, can downregulate DAT membrane expression via the stimulation of the $\mathrm{D}_{2}$ autoreceptors [66].

The present data support pharmacogenomics studies reporting associations between $D A T$ gene variations and clozapine efficacy in treatment resistant patients and in cognitive dysfunctions $[67,68]$. Thus, targeting DAT may be a paramount goal of APDs to overcome treatmentresistance in schizophrenia. A second observation supported by our data relates to our recent suggestions about the actual mechanisms of APD action [5]. We argue that the rise and fall of antipsychotic efficacy is driven by dynamic interactions of the endogenous dopamine and presynaptic $\mathrm{D}_{2}$ receptors. Specifically, increased tonic synaptic levels of dopamine in the striatum following the initial treatment with APDs would determine the stimulation of a dopamine $\mathrm{D}_{2}$ receptor reserve, which is defined as the difference between the total number of available $\mathrm{D}_{2}$ receptors $(100 \%)$ and the proportion of those $\mathrm{D}_{2}$ receptors bound by an APD at a dose within the therapeutic window (60-80\% blockade of central $\mathrm{D}_{2}$ receptors). The receptor reserve primarily includes presynaptic dopamine receptors, which tonically inhibit dopamine synthesis and release, and may mediate antipsychotic effects [5]. Present results showing an early suppression of mRNA DAT expression (Fig. 3e, f) along with an inhibition of vesicular release during antipsychotic efficacy (Fig. 5f, g) substantiate these interpretations.

By contrast, decreased tonic synaptic availability of dopamine, occurring during chronic APD treatment, is associated with a significant loss of APD efficacy. These effects may reflect a reduced stimulation of the $D_{2}$ receptor reserve triggered by the initial treatment [5]. Notably, dopamine release in the striatum is closely related to the firing of dopaminergic neurons in the midbrain, which was decreased in this study (Fig. 4c). Furthermore, DAT was upregulated during APD failure (Fig. 3e, h), thus, possibly increasing clearance of extracellular dopamine and contributing to a reduction of synaptic dopamine levels.

Reduced stimulation of $\mathrm{D}_{2}$ autoreceptors would predict that presynaptic neurons will be more sensitive to phasic dopamine release in response to stimulation. Consistent with this proposal we found increased $\mathrm{TH}$ expression (Supplementary Figure 1a, d), a potentiation of vesicular release (Fig. 5f, g) and a larger dopamine release in response to TP in those animals with lower basal dopamine levels (Fig. 2h, i).

Furthermore, local modulatory neurotransmission in the striatum affects release via direct action on axon terminals. Glutamatergic and cholinergic activity is sufficient to trigger striatal dopamine release independently of somatic firing [69]. Therefore, the decrease in synaptic dopamine driven by APDs in the striatum may make dopaminergic terminals more vulnerable to the excitatory effect of local glutamatergic transmission, which may result in increased field potentials (Fig. 4f). Also, synaptic neuroplasticity and related changes in multiple protein expression may pose viable interpretations of the role of APDs in structural brain changes observed in humans and in animals [70].

Our model of APDs efficacy and failure outlines quite a different perspective compared to traditional interpretations of antipsychotic mechanisms. The common view is that an "optimal" level of post-synaptic dopamine $\mathrm{D}_{2}$ receptor blockade with antipsychotics attenuates dopaminergic transmission at post-synaptic neurons [4, 71], which ameliorates the positive symptoms of schizophrenia. However, studies show that chronic APD treatment triggers 

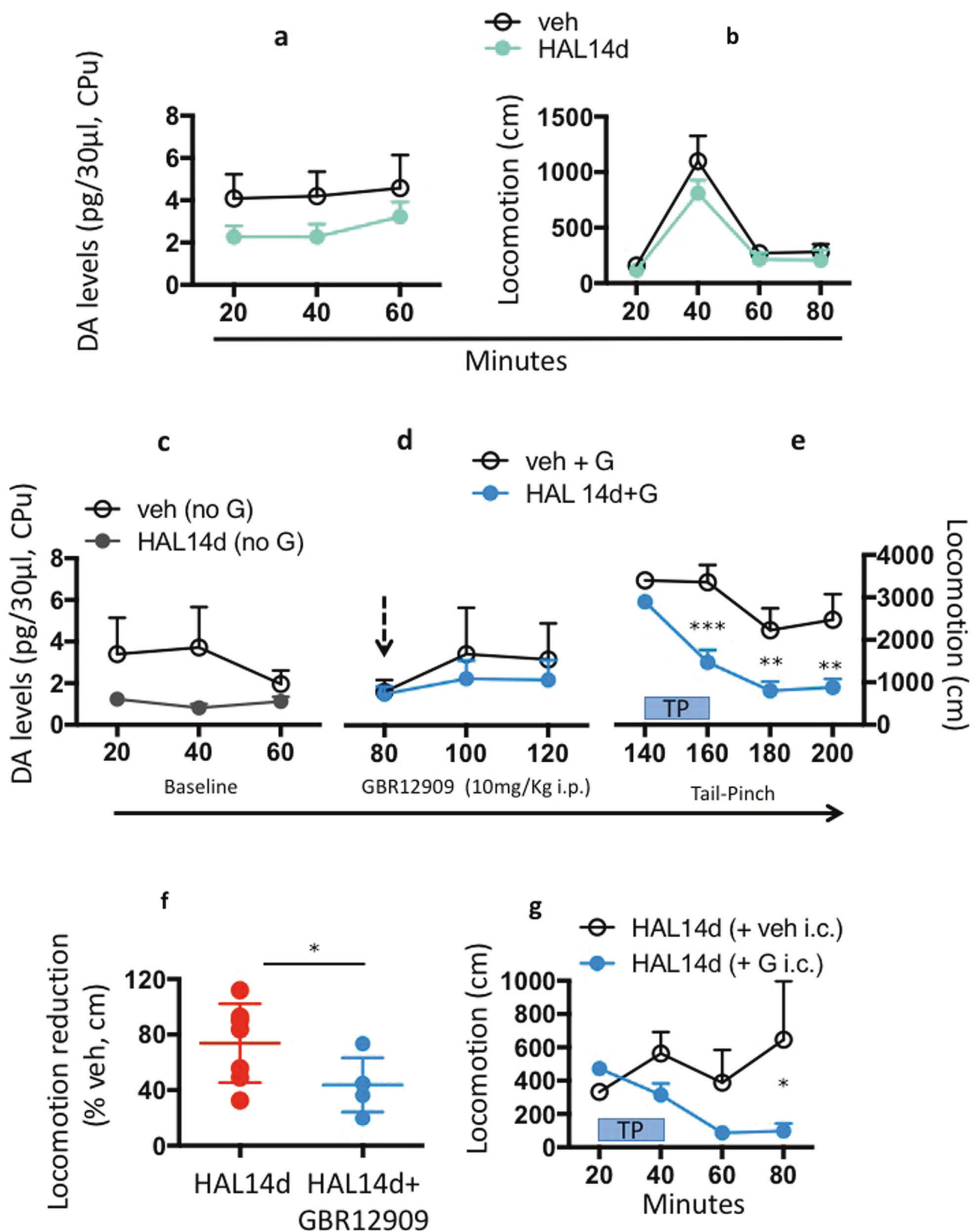

adaptations of post-synaptic dopamine $\mathrm{D}_{2}$ receptors, which undergo upregulation [28, 29, 31] and increased sensitivity for local dopaminergic signalling. This circumstance, known as dopamine supersensitivity [25, 72], is the hypothesized mechanism of antipsychotic treatment failure $[25,27,72]$. 
Fig. 6 Reversal of antipsychotic treatment failure. a Haloperidol (HAL) treatment for $14 \mathrm{~d}$ decreased the extracellular dopamine levels in the caudate-putamen $(\mathrm{CPu})(P<0.05$, main effect) and $\mathbf{b}$ is unable to block tail pinch (TP) induced hyperlocomotion $(P<0.0001$, main effect) compared to vehicle (veh) treated rats. $N=7$ /group. Data are means \pm S.E.M. c Similar to the previous experiment, HAL decreased the extracellular dopamine levels in the CPu compared with veh $(P<$ 0.05, main effect). d The systemic injection of GBR12909 $(10 \mathrm{mg} / \mathrm{kg}$, i.p.) replenished the extracellular dopamine to control group levels, and e reversed HAL failure, which was now sufficient to block TP induced hyperlocomotion compared to veh $(P<0.0001$, main effect). $N=5$ /group. Data are means \pm S.E.M. f The co-administration of GBR12909 (10 mg/kg, i.p.). $N=5-7 /$ group. Data are means \pm SD. g The intraCPu injection of the DAT blocker GBR12909 decreased the TP-induced hyperlocomotion in animals treated 14 days with HAL compared with control animals $(P<0.05$, main effect), thus mimicking the effect observed under systemic treatment of GBR12909. $N=4 /$ group. Data are means \pm S.E.M. $* P<0.05, * * P<0.01$, $* * * P<0.001$. Statistical significance represents post hoc comparison when not specified

Yet, changes in $\mathrm{D}_{2}$ receptor density are not consistently observed in patients previously exposed to antipsychotics [73]. APD treatment failure also occurs independently of any changes in $\mathrm{D}_{2}$ high affinity state receptor density in animal models [27]. In conclusion, whereas reducing the synaptic levels of dopamine has been the primary target of antipsychotics to reduce psychoses, our data suggest an apparent paradox that reduced dopamine signalling at presynaptic $D_{2}$ receptors is the actual cause of antipsychotic failure. Therefore, reverting dopamine levels in the dopaminergic synapse should reinstate APD efficacy. Here, we demonstrated this to be the case by blocking the clearance of synaptic dopamine using the DAT blocker GBR12909. This pharmacological intervention may be tested clinically as an augmentation strategy, alternative to increasing APD dosing or switching drugs, and possible abuse potential derived from this combination of treatments may be managed. Genetic variability in DAT expression as well as the age of patients at the start of treatment will affect APD response even if augmentation with a DAT blocker is used, simply because not all individuals will have a sufficient amount of DAT expression to mediate the necessary DAT blocker efficacy. Thus, an intriguing therapeutic strategy may be proposed based on viral expression of DAT in key brain areas to overcome treatment-resistance and equalize the therapeutic antipsychotic response across patients. Our study delineates mechanisms of APD efficacy and failure. It suggests a new strategy for personalized therapeutic approaches to overcome pathways to relapse, including APD tolerance, dopamine super-sensitivity psychosis, and treatment resistance.

\section{Limitations of the study}

$\mathrm{D}_{2}$ receptors exhibit high and low affinity states for dopamine agonists $\left(\mathrm{D}_{2}{ }^{\text {High }}, \mathrm{D}_{2}{ }^{\mathrm{Low}}\right)$ [74], which are not distinguished using current antagonist ligands [75]. Therefore, an increased prevalence of $\mathrm{D}_{2}{ }^{\text {High }}$ activated with APD treatment may lead to the dopamine supersensitivity underlying the antipsychotic loss of efficacy, despite an unaltered absolute total density of $\mathrm{D}_{2}$ receptors and net receptor occupancy. A previous study found that APD treatment failure was associated with a greater prevalence of $\mathrm{D}_{2}^{\text {High }}$ receptor, but this effect occurred only with high HAL doses [27]. Therefore, the role of the unbalanced $\mathrm{D}_{2}$ affinity state in mediating APD efficacy and failure in animal models remains to be determined.

We report herein that the $D_{2}$ receptor occupancy to microPET was in the clinical therapeutic range with HAL treatment, even though the drug was no longer effective in independent behavioral testing. Thus, we did not explicitly replicate HAL treatment failure in these animals. Our aim was to verify the $D_{2}$ receptor occupancy range during 14 days HAL treatment. The use of behavioral or pharmacological manipulations may have been confounding factors in our study. Such interventions can stimulate striatal dopamine release, thus perturbing $\mathrm{D}_{2}$ receptors availability in the HAL occupancy study after 14 days treatment, as shown in previous human PET studies [76].

Dopamine levels decreased after 6 days of HAL treatment, despite continued drug efficacy at that time point in multiple behavioral tests (Fig. 1). However, a decrease in dopamine levels occurred relative to the control group, but not compared with $14 \mathrm{~d}$ of HAL, which further lowered dopamine levels. We attribute this effect to possible different temporal kinetics that underlie changes in neurotransmitter levels and behavior. Therefore, reversal of antipsychotic inhibition in behavioral tests may occur with a different time-course than the reversal of extracellular dopamine. Particularly, the dopamine levels may decrease faster than the indices of behavioral APD efficacy. Furthermore, while the use of psychopathological naïve rodents may appear to limit the translational power of the present study, it should be noted that in absence of a clear understanding of the neurobiology of schizophrenia symptoms, which undermines face validity in experimental modelling, our pharmacological model yields evidence for neuroadaptations induced solely by the administration of APDs. These adaptations are very dynamic and time-locked with the onset and offset of antipsychotic efficacy. Nevertheless, the results of the present work may benefit from replications in psychopathological animal models.

Acknowledgements We thank Mr. Benedikt Quinger and Mr. Manuel Geisthoff for excellent technical assistance. We also thank Dr. Anna Kruyer for her comments to last draft of the paper. This work was funded by the intramural ELAN grants for research and teaching (Friedrich-Alexander-University Erlangen-Nürnberg) and supported by the Deutsche Forschungsgemeinschaft grants AM 488/1-1, MU 2789/7-1, AL 294/10-1, GR 4549/1-1, and by the G.A.-LienertFoundation. 


\section{Compliance with ethical standards}

Conflict of interest The authors declare that they have no conflict of interest.

Open Access This article is licensed under a Creative Commons Attribution 4.0 International License, which permits use, sharing, adaptation, distribution and reproduction in any medium or format, as long as you give appropriate credit to the original author(s) and the source, provide a link to the Creative Commons license, and indicate if changes were made. The images or other third party material in this article are included in the article's Creative Commons license, unless indicated otherwise in a credit line to the material. If material is not included in the article's Creative Commons license and your intended use is not permitted by statutory regulation or exceeds the permitted use, you will need to obtain permission directly from the copyright holder. To view a copy of this license, visit http://creativecommons. org/licenses/by/4.0/

\section{References}

1. Lieberman JA, Bymaster FP, Meltzer HY, Deutch AY, Duncan GE, Marx CE, et al. Antipsychotic drugs: comparison in animal models of efficacy, neurotransmitter regulation, and neuroprotection. Pharmacol Rev. 2008;60:358-403.

2. Johnstone EC, Crow TJ, Frith CD, Carney MW, Price JS. Mechanism of the antipsychotic effect in the treatment of acute schizophrenia. Lancet. 1978;1:848-51.

3. Kapur S, Seeman P. Antipsychotic agents differ in how fast they come off the dopamine D2 receptors. Implications for atypical antipsychotic action. J Psychiatry Neurosci. 2000;25:161-6.

4. Kapur S, Zipursky R, Jones C, Remington G, Houle S. Relationship between dopamine $\mathrm{D}(2)$ occupancy, clinical response, and side effects: a double-blind PET study of first-episode schizophrenia. Am J Psychiatry. 2000;157:514-20.

5. Amato D, Vernon AC, Papaleo F. Dopamine, the antipsychotic molecule: a perspective on mechanisms underlying antipsychotic response variability. Neurosci Biobehav Rev. 2017;85:146-59.

6. Lieberman JA, Stroup TS, McEvoy JP, Swartz MS, Rosenheck RA, Perkins DO, et al. Effectiveness of antipsychotic drugs in patients with chronic schizophrenia. N Engl J Med. 2005;353: 1209-23.

7. McEvoy JP, Lieberman JA, Stroup TS, Davis SM, Meltzer HY, Rosenheck RA, et al. Effectiveness of clozapine versus olanzapine, quetiapine, and risperidone in patients with chronic schizophrenia who did not respond to prior atypical antipsychotic treatment. Am J Psychiatry. 2006;163:600-10.

8. Stroup TS, Lieberman JA, McEvoy JP, Swartz MS, Davis SM, Rosenheck RA, et al. Effectiveness of olanzapine, quetiapine, risperidone, and ziprasidone in patients with chronic schizophrenia following discontinuation of a previous atypical antipsychotic. Am J Psychiatry. 2006;163:611-22.

9. Pilowsky LS, Costa DC, Ell PJ, Murray RM, Verhoeff NP, Kerwin RW. Clozapine, single photon emission tomography, and the D2 dopamine receptor blockade hypothesis of schizophrenia. Lancet. 1992;340:199-202.

10. Wolkin A, Barouche F, Wolf AP, Rotrosen J, Fowler JS, Shiue $\mathrm{CY}$, et al. Dopamine blockade and clinical response: evidence for two biological subgroups of schizophrenia. Am J Psychiatry. 1989;146:905-8.

11. Pilowsky LS, Costa DC, Ell PJ, Murray RM, Verhoeff NP, Kerwin RW. Antipsychotic medication, D2 dopamine receptor blockade and clinical response: a ${ }^{123}$ I IBZM SPET (single photon emission tomography) study. Psychol Med. 1993;23:791-7.
12. Kinon BJ, Chen L, Ascher-Svanum H, Stauffer VL, KollackWalker S, Zhou W, et al. Early response to antipsychotic drug therapy as a clinical marker of subsequent response in the treatment of schizophrenia. Neuropsychopharmacol. 2010;35:581-90.

13. Amato D, Natesan S, Kapur S, Müller CP. Haloperidol modulates noradrenergic responses to aversive stimulation depending on treatment duration. Behav Brain Res. 2011;221:311-3.

14. Amato D, Natesan S, Yavich L, Kapur S, Müller CP. Dynamic regulation of dopamine and serotonin responses to salient stimuli during chronic haloperidol treatment. Int J Neuropsychopharmacol. 2011;14:1327-39.

15. Amato D, Müller CP, Badiani A. Increased drinking after intrastriatal injection of the dopamine D2/D3 receptor agonist quinpirole in the rat. Psychopharmacol (Berl). 2012;223:457-63.

16. Gulbins E, Palmada M, Reichel M, Luth A, Bohmer C, Amato D, et al. Acid sphingomyelinase-ceramide system mediates effects of antidepressant drugs. Nat Med. 2013;19:934-8.

17. Tischbirek CH, Wenzel EM, Zheng F, Huth T, Amato D, Trapp S, et al. Use-dependent inhibition of synaptic transmission by the secretion of intravesicularly accumulated antipsychotic drugs. Neuron. 2012;74:830-44.

18. Heffner TG, Hartman JA, Seiden LS. A rapid method for the regional dissection of the rat brain. Pharmacol Biochem Behav. 1980;13:453-6.

19. Mukherjee J, Yang ZY, Das MK, Brown T. Fluorinated benzamide neuroleptics - III. Development of (S)-N-[(1-allyl-2-pyrrolidinyl) methyl]-5-(3-[ $\left.{ }^{18} \mathrm{~F}\right]$ fluoropropyl)-2,3-dimethoxy-benz-amide as an improved dopamine D-2 receptor tracer. Nucl Med Biol. 1995;22:283-96.

20. Cumming P, Maschauer S, Riss PJ, Tschammer N, Fehler SK, Heinrich MR, et al. Radiosynthesis and validation of ${ }^{18} \mathrm{~F}-\mathrm{FP}$ CMT, a phenyltropane with superior properties for imaging the dopamine transporter in living brain. J Cereb Blood Flow Metab. 2014;34:1148-56.

21. la Fougere C, Boning G, Bartmann H, Wangler B, Nowak S, Just $\mathrm{T}$, et al. Uptake and binding of the serotonin $5-\mathrm{HT}_{1 \mathrm{~A}}$ antagonist $\left[{ }^{18} \mathrm{~F}\right]-\mathrm{MPPF}$ in brain of rats: effects of the novel P-glycoprotein inhibitor tariquidar. Neuroimage. 2010;49: 1406-15.

22. Zhou Y, Endres CJ, Brasic JR, Huang SC, Wong DF. Linear regression with spatial constraint to generate parametric images of ligand-receptor dynamic PET studies with a simplified reference tissue model. Neuroimage. 2003;18:975-89.

23. Cumming P, Maschauer S, Riss PJ, Grill E, Pischetsrieder M, Kuwert $\mathrm{T}$, et al. Perturbed development of striatal dopamine transporters in fatty versus lean zucker rats: a follow-up small animal PET study. Mol Imaging Biol. 2015;17:521-8.

24. Klitenick MA, Taber MT, Fibiger HC. Effects of chronic haloperidol on stress- and stimulation-induced increases in dopamine release: tests of the depolarization block hypothesis. Neuropsychopharmacol. 1996;15:424-8.

25. Chouinard G, Jones BD. Neuroleptic-induced supersensitivity psychosis: clinical and pharmacologic characteristics. Am J Psychiatry. 1980;137:16-21.

26. Emsley R, Chiliza B, Asmal L, Harvey BH. The nature of relapse in schizophrenia. BMC Psychiatry. 2013;13:50.

27. Samaha AN, Seeman P, Stewart J, Rajabi H, Kapur S. "Breakthrough" dopamine supersensitivity during ongoing antipsychotic treatment leads to treatment failure over time. J Neurosci. 2007;27:2979-86.

28. Kornhuber J, Riederer P, Reynolds GP, Beckmann H, Jellinger K, Gabriel E. 3H-spiperone binding sites in post-mortem brains from schizophrenic patients: relationship to neuroleptic drug treatment, abnormal movements, and positive symptoms. J Neural Transm. 1989;75:1-10. 
29. Jenner P, Marsden CD. Chronic pharmacological manipulation of dopamine receptors in brain. Neuropharmacology. 1987;26 (7B):931-40.

30. Tarsy D, Baldessarini RJ. Behavioural supersensitivity to apomorphine following chronic treatment with drugs which interfere with the synaptic function of catecholamines. Neuropharmacology. 1974;13:927-40.

31. Silvestri S, Seeman MV, Negrete JC, Houle S, Shammi CM, Remington GJ, et al. Increased dopamine D2 receptor binding after long-term treatment with antipsychotics in humans: a clinical PET study. Psychopharmacol (Berl). 2000;152:174-80.

32. Seeman P, Weinshenker D, Quirion R, Srivastava LK, Bhardwaj SK, Grandy DK, et al. Dopamine supersensitivity correlates with D2High states, implying many paths to psychosis. Proc Natl Acad Sci USA. 2005;102:3513-8.

33. Wightman RM, Zimmerman JB. Control of dopamine extracellular concentration in rat striatum by impulse flow and uptake. Brain Res Brain Res Rev. 1990;15:135-44.

34. Gorard S. Introducing the mean absolute deviation 'effect' size. Int J Res Method Educ. 2014;38:105-14.

35. Siebert GA, Pond SM, Bryan-Lluka LJ. Further characterisation of the interaction of haloperidol metabolites with neurotransmitter transporters in rat neuronal cultures and in transfected COS-7 cells. Naunyn Schmiede Arch Pharmacol. 2000;361:255-64.

36. Salvatore MF, Calipari ES, Jones SR. Regulation of tyrosine hydroxylase expression and phosphorylation in dopamine transporter-deficient mice. ACS Chem Neurosci. 2016;7:941-51.

37. Grace AA. Dysregulation of the dopamine system in the pathophysiology of schizophrenia and depression. Nat Rev Neurosci. 2016;17:524-32.

38. Grace AA. Phasic versus tonic dopamine release and the modulation of dopamine system responsivity: a hypothesis for the etiology of schizophrenia. Neuroscience. 1991;41:1-24.

39. Grace AA, Bunney BS. The control of firing pattern in nigral dopamine neurons: burst firing. J Neurosci. 1984;4:2877-90.

40. Grace AA, Bunney BS. The control of firing pattern in nigral dopamine neurons: single spike firing. J Neurosci. 1984; 4:2866-76.

41. Chen BT, Rice ME. Novel Ca2+ dependence and time course of somatodendritic dopamine release: substantia nigra versus striatum. J Neurosci. 2001;21:7841-7.

42. Bjorklund A, Lindvall O. Dopamine in dendrites of substantia nigra neurons: suggestions for a role in dendritic terminals. Brain Res. 1975;83:531-7.

43. Jaffe EH, Marty A, Schulte A, Chow RH. Extrasynaptic vesicular transmitter release from the somata of substantia nigra neurons in rat midbrain slices. J Neurosci. 1998;18: $3548-53$.

44. Geffen LB, Jessell TM, Cuello AC, Iversen LL. Release of dopamine from dendrites in rat substantia nigra. Nature. 1976;260:258-60.

45. Rayport S, Sulzer D. Visualization of antipsychotic drug binding to living mesolimbic neurons reveals D2 receptor, acidotropic, and lipophilic components. J Neurochem. 1995;65:691-703.

46. Mani M,Ryan TA, Live imaging of synaptic vesicle release and retrieval in dopaminergic neurons. Front Neural Circuits. 2009;3:3

47. Wrosch JK, Groemer TW. Functional viability: measurement of synaptic vesicle pool sizes. Methods Mol Biol. 2017;1601: 195-204.

48. Rizzoli SO, Betz WJ. Synaptic vesicle pools. Nat Rev Neurosci. 2005;6:57-69.

49. Waters N, Lofberg L, Haadsma-Svensson S, Svensson K, Sonesson C, Carlsson A. Differential effects of dopamine D2 and D3 receptor antagonists in regard to dopamine release, in vivo receptor displacement and behaviour. J Neural Transm Gen Sect. 1994;98:39-55.
50. Preti A. Vanoxerine national institute on drug abuse. Curr Opin Investig Drugs. 2000;1:241-51.

51. Singh S. Chemistry, design, and structure-activity relationship of cocaine antagonists. Chem Rev. 2000;100:925-1024.

52. Izenwasser S, Werling LL, Cox BM. Comparison of the effects of cocaine and other inhibitors of dopamine uptake in rat striatum, nucleus accumbens, olfactory tubercle, and medial prefrontal cortex. Brain Res. 1990;520:303-9.

53. Sedaghat F, Gotzamani-Psarrakou A, Dedousi E, Arnaoutoglou M, Psarrakos K, Baloyannis I, et al. Evaluation of dopaminergic function in frontotemporal dementia using I-FP-CIT single photon emission computed tomography. Neurodegener Dis. 2007;4: $382-5$.

54. Chang WH, Chen KC, Lee IH, Chi MH, Chen PS, Yao WJ, et al. Unaltered dopamine transporter availability in drug-naive patients with schizophrenia after 6 months of antipsychotics treatment: a naturalistic study. J Clin Psychopharmacol. 2017;37:21-26.

55. Fusar-Poli P, Meyer-Lindenberg A. Striatal presynaptic dopamine in schizophrenia, Part I: meta-analysis of dopamine active transporter (DAT) density. Schizophr Bull. 2013;39:22-32.

56. Laakso A, Bergman J, Haaparanta M, Vilkman H, Solin O, Syvalahti E, et al. Decreased striatal dopamine transporter binding in vivo in chronic schizophrenia. Schizophr Res. 2001;52:115-20.

57. Yoder KK, Hutchins GD, Morris ED, Brashear A, Wang C, Shekhar A. Dopamine transporter density in schizophrenic subjects with and without tardive dyskinesia. Schizophr Res. 2004;71:371-5.

58. Markota M, Sin J, Pantazopoulos H, Jonilionis R, Berretta S. Reduced dopamine transporter expression in the amygdala of subjects diagnosed with schizophrenia. Schizophr Bull. 2014;40:984-91.

59. Bannon MJ, Whitty CJ. Age-related and regional differences in dopamine transporter mRNA expression in human midbrain. Neurology. 1997;48:969-77.

60. Volkow ND, Ding YS, Fowler JS, Wang GJ, Logan J, Gatley SJ, et al. Dopamine transporters decrease with age. J Nucl Med. 1996;37:554-9.

61. Rieckmann A, Hedden T, Younger AP, Sperling RA, Johnson KA, Buckner RL. Dopamine transporter availability in clinically normal aging is associated with individual differences in white matter integrity. Hum Brain Mapp. 2016;37:621-31.

62. Reis Marques T, Taylor H, Chaddock C, Dell'acqua F, Handley R, Reinders AA, et al. White matter integrity as a predictor of response to treatment in first episode psychosis. Brain. 2014;137 (Pt 1):172-82.

63. Szeszko PR, Robinson DG, Ikuta T, Peters BD, Gallego JA, Kane J, et al. White matter changes associated with antipsychotic treatment in first-episode psychosis. Neuropsychopharmacol. 2014;39:1324-31.

64. Zahniser NR, Sorkin A. Rapid regulation of the dopamine transporter: role in stimulant addiction? Neuropharmacology. 2004;47 (Suppl 1):80-91.

65. Nikolaus S, Antke C, Kley K, Beu M, Wirrwar A, Müller HW. Pretreatment with haloperidol reduces (123)I-FP-CIT binding to the dopamine transporter in the rat striatum: an in vivo imaging study with a dedicated small-animal SPECT camera. J Nucl Med. 2009;50:1147-52.

66. Kimmel HL, Joyce AR, Carroll FI, Kuhar MJ. Dopamine D1 and D2 receptors influence dopamine transporter synthesis and degradation in the rat. J Pharmacol Exp Ther. 2001;298:129-40.

67. Szekeres G, Keri S, Juhasz A, Rimanoczy A, Szendi I, Czimmer C, et al. Role of dopamine D3 receptor (DRD3) and dopamine transporter (DAT) polymorphism in cognitive dysfunctions and therapeutic response to atypical antipsychotics in patients with schizophrenia. Am J Med Genet B Neuropsychiatr Genet. 2004;124B:1-5. 
68. Xu M, Xing Q, Li S, Zheng Y, Wu S, Gao R, et al. Pharacogenetic effects of dopamine transporter gene polymorphisms on response to chlorpromazine and clozapine and on extrapyramidal syndrome in schizophrenia. Prog Neuropsychopharmacol Biol Psychiatry. 2010;34:1026-32.

69. Cachope R, Cheer JF. Local control of striatal dopamine release. Front Behav Neurosci. 2014;8:188.

70. Vernon AC, Natesan S, Crum WR, Cooper JD, Modo M, Williams SC, et al. Contrasting effects of haloperidol and lithium on rodent brain structure: a magnetic resonance imaging study with postmortem confirmation. Biol Psychiatry. 2012;71:855-63.

71. Seeman P, Lee T, Chau-Wong M, Wong K. Antipsychotic drug doses and neuroleptic/dopamine receptors. Nature. 1976;261:717-9.

72. Iyo $M$, Tadokoro $S$, Kanahara $N$, Hashimoto $T$, Niitsu $T$, Watanabe $\mathrm{H}$, et al. Optimal extent of dopamine D2 receptor occupancy by antipsychotics for treatment of dopamine supersensitivity psychosis and late-onset psychosis. J Clin Psychopharmacol. 2013;33:398-404.

73. Laruelle M. Imaging dopamine transmission in schizophrenia. A review and meta-analysis. Q J Nucl Med: 1998;42:211-21.

74. Cumming P. Absolute abundances and affinity states of dopamine receptors in mammalian brain: a review. Synapse. 2011;65: 892-909.

75. Seeman P. Dopamine agonist radioligand binds to both D2High and D2Low receptors, explaining why alterations in D2High are not detected in human brain scans. Synapse. 2012;66:88-93.

76. Abi-Dargham A, Rodenhiser J, Printz D, Zea-Ponce Y, Gil R, Kegeles LS, et al. Increased baseline occupancy of D2 receptors by dopamine in schizophrenia. Proc Natl Acad Sci USA. 2000;97:8104-9. 